\title{
LOWER MANTLE HIGH-VELOCITY ZONE BENEATH THE KURILS AS INFERRED FROM P-WAVE TRAVEL TIME AND AMPLITUDE DATA
}

\author{
Daisuke SuETsugu* \\ Department of Geophysics, Faculty of Science, \\ Hokkaido University, Sapporo, Japan \\ (Received May 26, 1989; Revised October 4, 1989)
}

We attempt to detect a high-velocity zone in the lower mantle beneath the Okhotsk Sea by analyzing travel time and amplitude data for teleseismic P-waves from intermediate and deep earthquakes in the Kurils. Travel time residuals with respect to the J-B tables are obtained by correcting ISC arrival time data for the Earth's ellipticity, station anomaly, and station elevation and are then inverted to obtain a P-velocity model for depths shallower than $1,250 \mathrm{~km}$ in the Kuril subduction zone. The velocity model exhibits a dipping high-velocity zone down to a depth of $1,200 \mathrm{~km}$ in the lower mantle immediately beneath the Kuril deepest seismicity. The velocity in the dipping zone is $2-3 \%$ higher than the ambient lower mantle. Resolution analysis supports the existence of a slablike high-velocity zone, but indicates that the depth extent of the zone cannot be well resolved by travel time data alone. We further constrain the velocity model by analyzing amplitude data, which are more sensitive to fine velocity structure than travel times. After correcting the amplitude data for the source radiation pattern, geometrical spreading, station anomaly, and instrument response, we obtain the amplitude anomaly due to laterally heterogeneous earth structure. The amplitude at a period of $1.5 \mathrm{~s}$ decreases by a factor of 2 to 4 at stations in the distance range between $50^{\circ}-65^{\circ}$ and with azimuths perpendicular to the Kuril trench. To separate the effects of slab structure from those of large-scale mantle heterogeneity, we model the amplitude anomaly using a hybrid method combining a finite element (FEM) scheme with geometrical optics. The high-velocity zone obtained by the travel time inversion produces an amplitude reduction for the short-period $\mathrm{P}$-waves which is comparable to the observed amplitude reduction. This suggests that the observed amplitude anomaly is primarily due to the lower mantle high-velocity zone.

Comparison of the observed and theoretical amplitudes shows that a much larger velocity gradient is required near the upper boundary of the dipping high-velocity zone than near the lower boundary. A high-velocity zone with a maximum depth of $1,000 \mathrm{~km}$, thickness of $150 \mathrm{~km}$, and velocity contrast of $3.5 \%$ gives the best fit to the amplitude data. Similarities in the velocity structure and the dip angle between the lower mantle high-velocity zone found by the present

* Present address: Department of Geophysics, Faculty of Science, The University of Tokyo, Tokyo, Japan. 
study and the upper mantle slab suggest that the former represents a lithospheric slab penetrating into the lower mantle.

\section{Introduction}

If slabs penetrate below depths of $700 \mathrm{~km}$, there should be velocity anomalies extending below the deepest focus earthquakes. Such a lower mantle slab may be detected by analyzing teleseismic body wave data from deep earthquakes. Previous studies have used teleseismic body wave travel time (JORDAN, 1977; CrEAGER and JoRdAN, 1984, 1986; Fischer et al., 1988) and waveform (Silver and ChAN, 1986; BECK and LAY, 1986) data from Kuril deep events to infer the existence of lower mantle slab penetration beneath the Okhotsk Sea.

Since JORDAN (1977), extensive studies have been conducted to investigate lower mantle slab penetration beneath the Kuril subduction zone using residual sphere analysis (CREAGER and JORDAN, 1984, 1986; FISCHER et al., 1988), in which a smoothing filter is applied to estimate the residuals due to near-source velocity heterogeneity, which are manifested as low wave-number components on the residual sphere. Theoretical residual spheres are computed by tracing rays through three-dimensional thermal models (e.g., Toksöz et al., 1971) of the slab and are compared to the observed residual spheres. CREAGER and JORDAN $(1984,1986)$ concluded that velocity models with slab penetration to depths exceeding $1,000 \mathrm{~km}$ provided adequate fits to the observed residual spheres and that the P-velocity in the lower mantle slab is 3 to $4 \%$ faster than that in the surrounding mantle.

SILVER and CHAN (1986) observed broadened SH wave arrivals traveling from Kuril deep events along the strike of the subduction zone. They attributed the broadening to $\mathrm{P}$-wave multipathing induced by a high-velocity slab penetrating into the lower mantle. BECK and LAY (1986) analyzed SH waveforms from Kuril deep events at receivers with a wider range of azimuths than those used by SILVER and CHAN (1986), and studied the correlation of waveform broadening with azimuth. BECK and LAY (1986) found that the broadening was largest at azimuths along the strike of the Kuril trench and suggested that a high-velocity slab descending into the lower mantle beneath the Okhotsk Sea is responsible for the largest broadening. VIDALE (1987) and CORMIER (1989) modeled waveform broadening due to a lower mantle high-velocity slab applying a finite difference method (FDM) and a Gaussian beam method, respectively, and using velocity structures constructed by the thermal modeling.

Since the results of the previous studies suggesting slab penetration into the lower mantle have profound implications for mantle dynamics, it is important to critically assess the reliability of the slab penetration hypothesis by using alternative approaches. There are several problems in the previous studies: (1) The smoothing filter applied to the residual sphere cannot differentiate between travel time anomalies due to slab penetration and large-scale velocity heterogeneity located far from the source region, because both contribute similarly to the low wave-number 
components on the residual sphere. (2) Most previous studies do not perform resolution analysis, which is essential to determine quantitatively the extent to which the travel time data constrain the lower mantle velocity structure. (3) The thermal modeling used in the previous studies requires the values of the thermal diffusitivity coefficient and the temperature derivatives of seismic wave velocities for lower mantle material, which are not well known currently.

Recently several studies have attempted to overcome the above difficulties. KAMTYA et al. (1988) applied tomographic inversion to ISC P-wave arrival time data to infer the mantle structure in and around Japan (relying on neither thermal modeling nor a smoothing filter) and conducted resolution analysis. Their approach removes the effects of the velocity structure outside the studied area from the travel time residual data. They concluded that a slab-like high-velocity zone exists below the deep events beneath the Japan trench, but their study did not cover the Kuril subduction zone fully.

\section{Present Study}

The purpose of the present study is to obtain a P-wave velocity model for the upper $1,200 \mathrm{~km}$ of the mantle beneath the Kuril subduction zone by analyzing P-wave travel time and amplitude data from Kuril intermediate and deep events. We conduct a tomographic inversion of the travel time data, and study the resolving power of the travel time data quantitatively. Our analysis does not require thermal modeling.

The amplitude anomalies due to laterally heterogeneous earth structure are obtained from the observed amplitudes at teleseismic stations. We study the extent to which the velocity model we obtain from the travel time inversion is capable of explaining the observed amplitude anomalies. Including amplitude data in our analysis improves the resolution of the velocity structure, since the amplitude anomaly is sensitive to the spatial gradients of the velocity anomaly.

\section{P-Wave Travel Time Analysis}

\subsection{Data}

In the travel time analysis we use P-wave arrival times reported in the ISC (International Seismological Centre) Bulletin. We analyze intermediate and deep earthquakes which occurred in the area from $44^{\circ} \mathrm{N}$ to $51^{\circ} \mathrm{N}$ latitude and from $146^{\circ} \mathrm{E}$ to $150^{\circ} \mathrm{E}$ longitude during the period from 1971 to 1982 . We pick earthquakes for which there is good azimuthal coverage. The hypocentral parameters determined by the ISC are listed in Table 1 and the hypocenters are shown in Fig. 1.

Rather than using all of the P times reported in the ISC Bulletin, we select data that meet the following criteria. (1) We use only local data (epicentral distances less than $10^{\circ}$ ) and teleseismic data (distances between $30^{\circ}$ and $90^{\circ}$ ). We thus discard data affected by upper mantle discontinuities and core diffracted waves. (2) We 
Table 1. Earthquakes studied in the travel time analysis.

\begin{tabular}{|c|c|c|c|c|c|c|c|c|c|c|}
\hline \multirow{2}{*}{ Event } & \multicolumn{3}{|c|}{ Date } & \multicolumn{3}{|c|}{ Origin time } & \multirow{2}{*}{$\begin{array}{l}\text { Latitude } \\
\text { (deg) }\end{array}$} & \multirow{2}{*}{$\begin{array}{l}\text { Longitude } \\
\text { (deg) }\end{array}$} & \multirow{2}{*}{$\begin{array}{l}\text { Depth } \\
(\mathrm{km})\end{array}$} & \multirow{2}{*}{$m_{\mathrm{b}}$} \\
\hline & $\mathrm{d}$ & $\mathrm{m}$ & $\mathrm{y}$ & $\mathrm{hr}$ & $\min$ & $\mathrm{s}$ & & & & \\
\hline 1 & 29 & 1 & 78 & 2 & 5 & 1.44 & 45.871 & 149.214 & 152.7 & 5.4 \\
\hline 2 & 9 & 4 & 74 & 13 & 11 & 23.63 & 45.394 & 148.414 & 161.2 & 5.4 \\
\hline 3 & 29 & 3 & 76 & 19 & 48 & 39.69 & 45.968 & 149.512 & 165.5 & 5.4 \\
\hline 4 & 8 & 5 & 81 & 6 & 44 & 49.17 & 44.774 & 146.187 & 167.0 & 5.1 \\
\hline 5 & 10 & 6 & 79 & 16 & 55 & 59.79 & 46.895 & 148.170 & 291.6 & 4.9 \\
\hline 6 & 21 & 6 & 78 & 11 & 10 & 38.72 & 48.264 & 148.665 & 401.9 & 5.8 \\
\hline 7 & 20 & 12 & 74 & 16 & 38 & 55.33 & 49.754 & 149.747 & 425.3 & 5.0 \\
\hline 8 & 4 & 12 & 77 & 11 & 39 & 2.27 & 48.195 & 146.656 & 475.0 & 4.9 \\
\hline 9 & 22 & 12 & 80 & 20 & 31 & 43.99 & 48.169 & 146.236 & 480.5 & 5.3 \\
\hline 10 & 6 & 2 & 81 & 16 & 47 & 8.49 & 48.278 & 146.385 & 500.8 & 5.3 \\
\hline 11 & 29 & 1 & 82 & 0 & 2 & 4.48 & 49.127 & 147.884 & 555.6 & 5.0 \\
\hline 12 & 21 & 8 & 72 & 6 & 23 & 48.58 & 49.460 & 147.076 & 585.1 & 5.9 \\
\hline 13 & 6 & 3 & 72 & 18 & 50 & 16.78 & 50.130 & 148.800 & 591.5 & 5.4 \\
\hline 14 & 25 & 1 & 79 & 21 & 3 & 20.92 & 50.450 & 148.917 & 593.5 & 5.3 \\
\hline 15 & 28 & 7 & 73 & 20 & 6 & 35.36 & 50.439 & 148.918 & 601.1 & 5.5 \\
\hline 16 & 27 & 11 & 82 & 9 & 55 & 38.89 & 50.183 & 147.764 & 638.4 & 5.5 \\
\hline
\end{tabular}

(a)

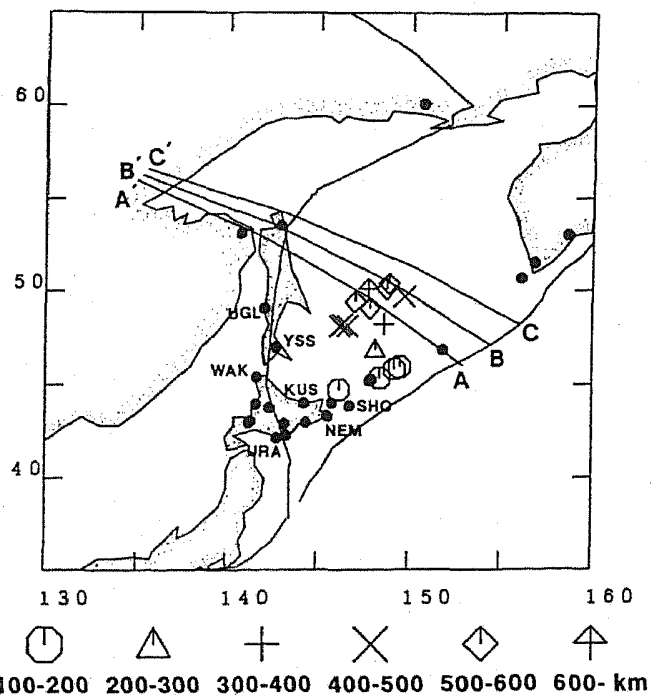

(b)

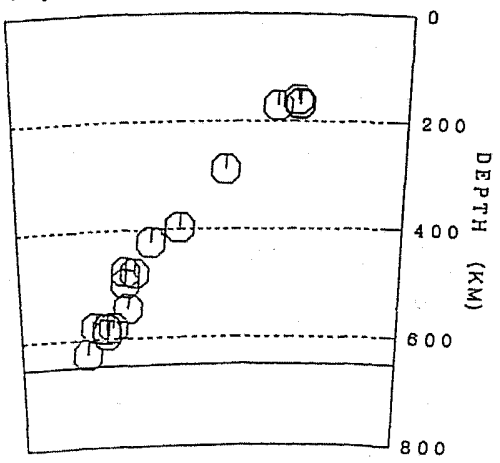

Fig. 1. The earthquakes used in the travel time analysis. (a) Epicenters. Symbol convention is indicated in the figure. Solid curves $\mathrm{A}-\mathrm{A}^{\prime}, \mathrm{B}-\mathrm{B}^{\prime}$, and $\mathrm{C}-\mathrm{C}^{\prime}$ indicate cross sections shown in Figs. 5, 6, and 7, respectively. Small dots are local stations used in the present study. (b) Hypocenters projected onto a cross section taken perpendicular to the strike of the Kuril arc. 
select data for arrivals designated as 'impulsive' by the ISC and for which the arrival times are given to a precision of $0.1 \mathrm{~s}$. Data whose residuals reported by the ISC are greater than $2 \mathrm{~s}$ are removed from the data set. Local data with a precision of $1.0 \mathrm{~s}$ are also included, because they constrain the focal depth. We assign a larger a priori standard error to data with a precision of $1.0 \mathrm{~s}$ than to data with a precision of $0.1 \mathrm{~s}$.

We account for hydrostatic ellipticity using the table of DzIEwonsKr and GILBERT (1976), and account for near-receiver structure beneath teleseismic stations using the azimuth-dependent station anomalies given by DzIEWONSKI and ANDERSON (1983). We also correct the arrival time data for the effect of station elevation. We then relocate the events using the corrected arrival times and the JEFFREYS-BULLEN tables (1940). We assume an a priori standard error of $0.2 \mathrm{~s}$ for arrivals given to a precision of $0.1 \mathrm{~s}$ and an a priori error of $0.5 \mathrm{~s}$ for arrivals rounded to the nearest second.

The travel time residuals for the relocated hypocenters provide the basic data for our study of laterally heterogeneous structure. We exclude residuals for stations in the azimuthal range near the strike of the Kuril trench $\left(0^{\circ}-40^{\circ}\right.$ and $220^{\circ}-280^{\circ}$ measured clockwise from the north), because the rays to these stations may be strongly distorted by the high-velocity slab (SLEEP, 1973; SILVER and CHAN, 1986) and we do not conduct exact three-dimensional ray tracing. The total amount of data used in the travel time inversion is 1458 .

We show typical examples of residual spheres (DAvIES and MCKENZIE, 1969) for events with focal depths of 150,480 , and $580 \mathrm{~km}$ in Fig. 2. Data coverage in the NW quadrant of the sphere is critical for resolving the velocity anomaly in the down-dip direction of the Kuril slab. Figure 2 indicates that sufficient data remain in the NW quadrant even after applying the above strict criteria for data selection.

Figure 3(a) shows a map view of the P-wave ray paths used in the travel time analysis. The ray paths are calculated for Jeffreys' P-velocity model. The cross section (Fig. 3(b)) demonstrates that there is excellent coverage of the down-dip extension of the subducting slab. However, Fig. 3(b) also suggests that it may be difficult to determine the spatial location of the velocity anomalies in the down-dip direction because the rays are basically parallel to the slab. Resolution analysis is thus essential for interpreting the results of the inversion.

\subsection{Inverse Method}

Because the travel time residual is the integral of the velocity heterogeneity along the entire ray, it is difficult to determine the location of the velocity anomalies. In the present study we assume that velocity heterogeneity located near the source region is responsible for all of the travel time residuals obtained by the above relocation, and determine the velocity model for the near-source region which provides the best fit to the travel time data. The validity of this assumption will be examined by the $\mathrm{P}$-wave amplitude analysis in the later part of the present paper. 
(a) $\underset{h=150 \mathrm{~km}}{\mathrm{EVN}}$
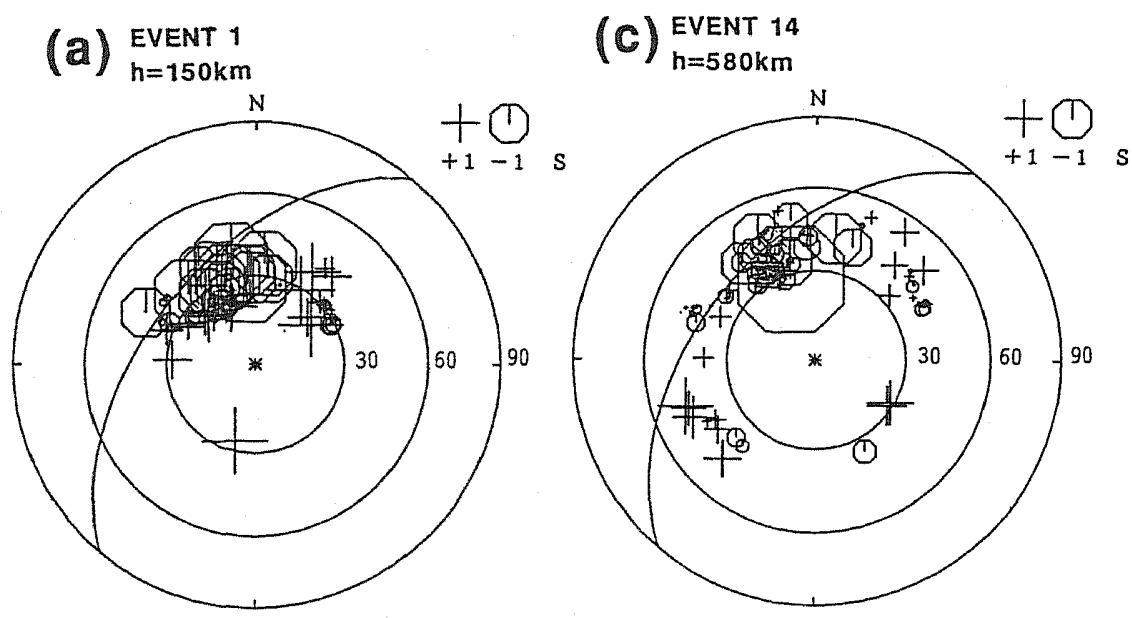

(b) $\underset{h=480 \mathrm{~km}}{\text { EVENT } 9}$

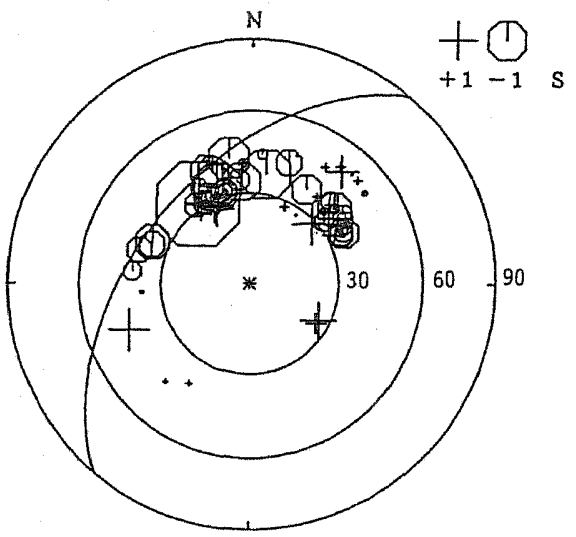

Fig. 2. Residual spheres for events 1 (a), 9 (b), and 14 (c). Equal-area projection of the lower-half hemisphere is shown. Crosses denote positive residuals and circles negative residuals. Symbol size is proportional to the magnitude of the residual. Concentric circles and associated figures indicate takeoff angles measured from the downward vertical.

Figure 4 depicts our parameterization for the $\mathrm{P}$-wave velocity structure beneath the Okhotsk Sea. Because our main purpose is to obtain a lower mantle velocity model, we use only a small number of parameters for the upper mantle: the slowness perturbations at the nodes located along the central axis of the upper mantle lithospheric slab and those in the ambient mantle. The geometry of the upper mantle slab is inferred from the hypocentral distribution of the Kuril intermediate and deep events with magnitude greater than 4.5 (from the ISC Bulletins for 1971-1982). The slab is assumed to dip at an angle of $40^{\circ}$ at the Earth's surface and to bend 
(a)

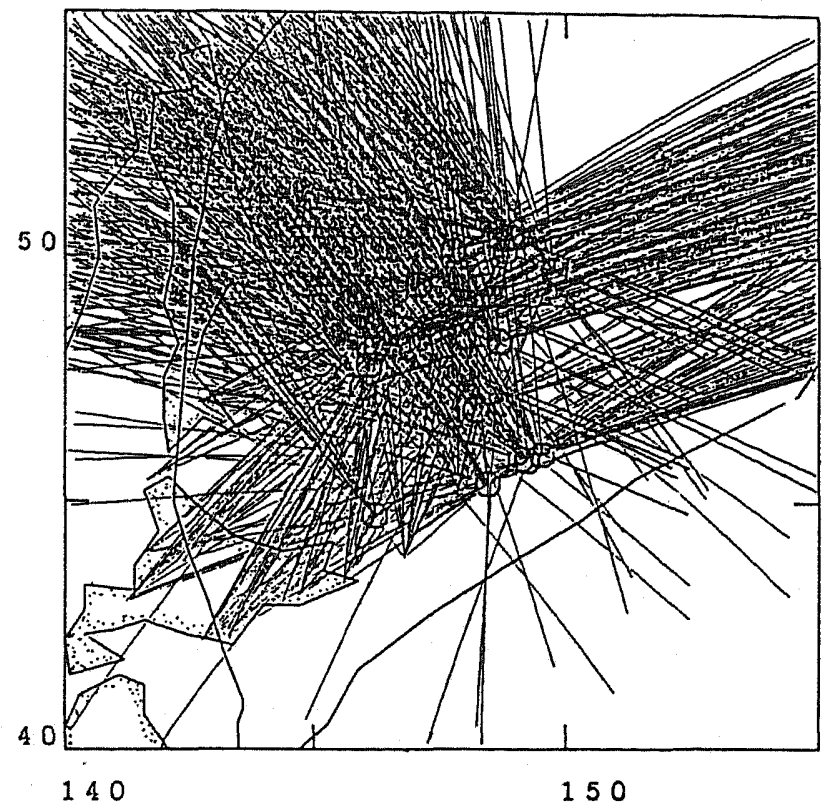

(b)

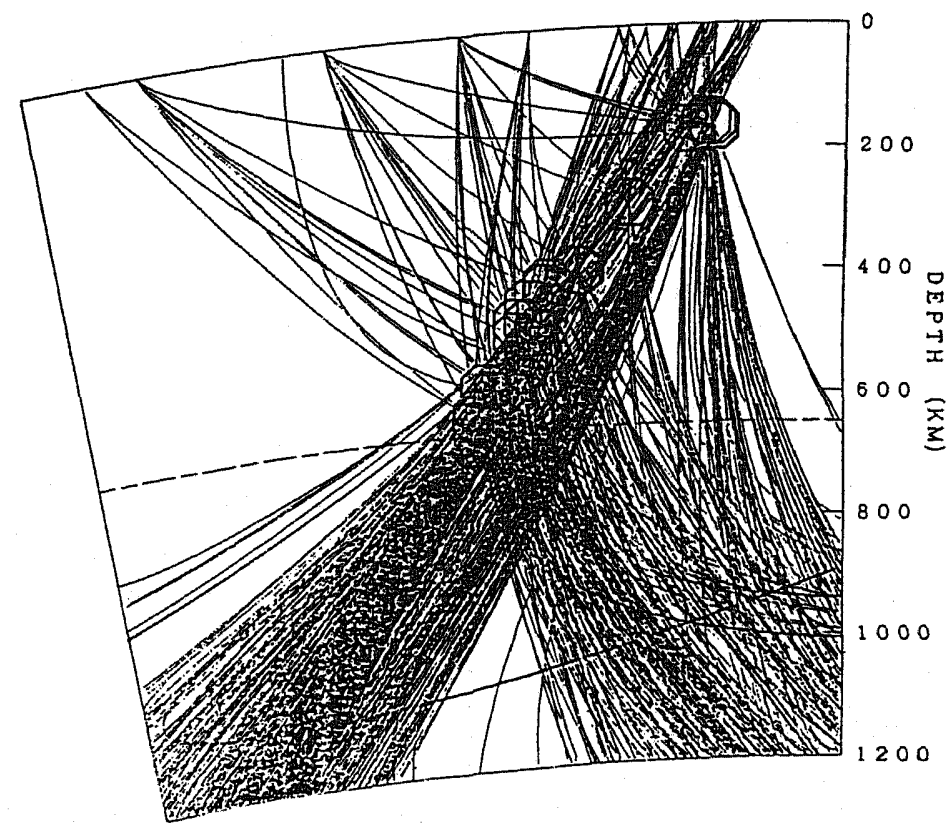

Fig. 3. P-wave ray paths running through the mantle above $1,250 \mathrm{~km}$. Circles indicate the events used in the present study. (a) Projection onto the Earth's surface. (b) Projection onto a cross section taken perpendicular to the strike of the Kuril arc. 


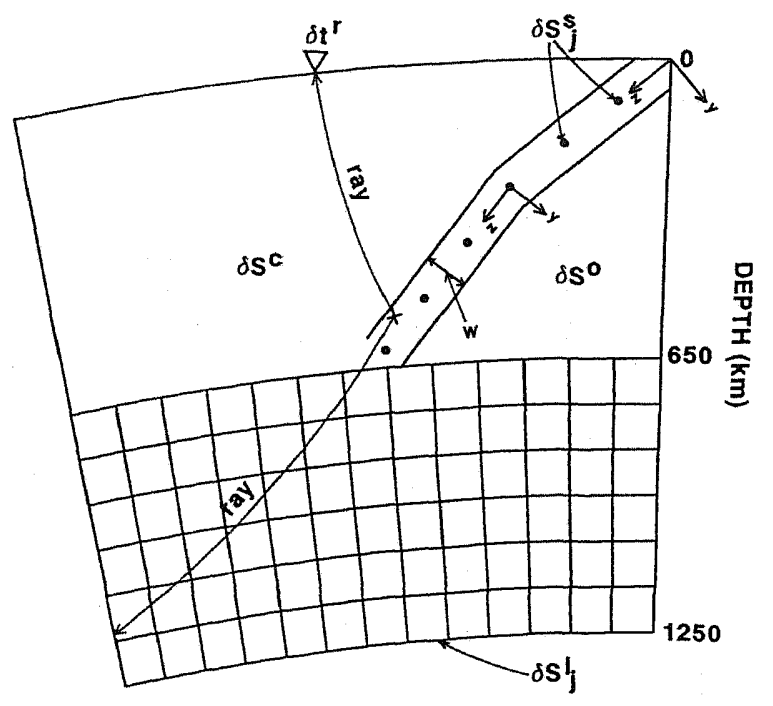

Fig. 4. Schematic illustration of the parameterization which describes the mantle above $1,250 \mathrm{~km}$ in the Kuril subduction zone. See text for details.

downward by $15^{\circ}$ at a depth of $300 \mathrm{~km}$. A three-dimensional model of the Kuril slab is constructed by an axial rotation of the two-dimensional slab about an arc pole located at point $\left(58.243^{\circ} \mathrm{N}, 127.993^{\circ} \mathrm{E}\right)$. This pole best delineates the geometry of the Kuril seismic zone (ENGDAHL et al., 1977). We express the slowness perturbation within the upper mantle slab using the following analytical form in the slab centered coordinate system $(y, z)$ (Fig. 4):

$$
\delta S(y, z)=S_{0}(r) \cdot F(y, z)
$$

and

$$
F(y, z)=\left\{\sum_{j=1}^{M^{s}} \delta S_{j}^{S} \phi_{j}(z)\right\} \cdot \cos (\pi y / W)
$$

where $S_{0}(r)$ is the slowness of the spherically symmetric reference Earth model, $\delta S_{j}^{S}$ $\left(j=1, M^{S}\right)$ is the slowness perturbation at the $j$-th node with respect to the reference model, and $\phi_{j}(z)$ are cardinal spline functions (SCHulTZ, 1973). We use Jeffreys' P-wave velocity model as $S_{0}(r)$. The slab width $W$ is fixed to be $100 \mathrm{~km}$, and the interval between nodes is set to $150 \mathrm{~km}$. The nodes are indicated by solid dots in Fig. 4. Changes of the slab width $W$ by up to $50 \mathrm{~km}$ do not change our results. The ambient upper mantle is allowed to have different velocities above and under the slab. The velocity perturbation is assumed to be uniform in each part of the ambient mantle.

We discretize the lower mantle beneath the subduction zone into many blocks of an equal size, since we do not have any a priori information on the velocity 
heterogeneity in the lower mantle. The block size in the lower mantle down to a depth of $1,250 \mathrm{~km}$ is $1^{\circ} \times 1^{\circ} \times 100 \mathrm{~km}$.

Hypocentral parameters are treated as the parameters to be determined by the inversion since the source locations may be subject to systematic errors due to lateral heterogeneity of the subduction zone (e.g., UTSU, 1975). Station anomalies for the local stations (in Hokkaido, the Kuril Islands, Sakhalin, and Kamchatka) are also parameters to be determined by the inversion, as it is necessary to account for the velocity anomalies in the crust and uppermost mantle beneath the local stations.

The travel time residual $\delta t_{i}$ of the $i$-th ray from the $k$-th event is

$$
\delta t_{i}=\int_{L_{i}} \delta S(y, z) \mathrm{d} l+\sum_{j=1}^{4}\left(\partial t_{i} / \delta h_{j}^{k}\right) \cdot \partial h_{j}^{k}+\delta t^{r} \cdot r_{i} \quad(i=1, N)
$$

where $\delta h_{j}^{k}(j=1,4)$ denotes the perturbations in the source parameters (latitude, longitude, depth, and origin time) of the $k$-th event, $\delta t^{r}$ denotes the local station anomalies, and $N$ is the number of travel time data. We set $r_{i}=0$ for teleseismic data and $r_{i}=1$ for local data. The line integral of the slowness anomalies $\delta S$ and the partial derivatives of the travel time with respect to the source parameters are computed using the ray path $L_{i}$. We compute the ray paths for Jeffreys' P-velocity model. We do not take into consideration ray path distortions due to lateral heterogeneity, since the three-dimensional ray tracing is very time-consuming. Using the above parameterization, we express Eq. (3) as

$$
\begin{aligned}
\delta t_{i}= & \sum_{j=1}^{M^{S}}\left\{\int_{L_{i}} S_{0}(r) \phi_{j}(z) \cos (\pi y / W) \mathrm{d} l\right\} \cdot \delta S_{j}^{S}+\delta S^{o} \cdot l_{i}^{o}+\delta S^{C} \cdot l_{i}^{C}+\sum_{j=1}^{M^{L}} \delta S_{j}^{L} \cdot l_{i j}^{L} \\
& +\sum_{j=1}^{4}\left(\partial t_{i} / \partial h_{j}^{k}\right) \cdot \delta h_{j}^{k}+\delta t^{r} \cdot r_{i} \quad(i=1, N)
\end{aligned}
$$

where $l$ denotes the length of the fractional ray path and $\mathrm{d} l$ is a line element of the ray path $L_{i}$. The superscripts $S, O, C$, and $L$ indicate slab, oceanic upper mantle, continental upper mantle, and lower mantle, respectively. $M^{L}$ is the number of blocks in the lower mantle. The integral is computed along the ray path only within the slab. The model parameters to be determined are: the slowness anomalies in the upper mantle slab $\delta S_{j}^{S}\left(j=1, M^{S}\right)$; in the ambient upper mantle $\delta S^{o}$ and $\delta S^{c}$; in the lower mantle $\delta S_{j}^{L}\left(j=1, M^{L}\right)$; the perturbations of the source parameters $\delta h_{j}^{k}$ $(j=1,4)$; and the station anomalies $\delta t^{r}$ for the local stations. We rewrite Eq. (4) in matrix notation

$$
\delta \boldsymbol{d}=\boldsymbol{G} \cdot \delta \boldsymbol{m} .
$$

The data vector $\delta \boldsymbol{d}$ and the model vector $\delta \boldsymbol{m}$ are composed of the observed travel time residuals and the perturbations to the model parameters, respectively. The matrix $G$ represents the partial derivatives of the data with respect to the model parameters. To stabilize the inversion we introduce an a priori data covariance 
matrix $C_{d_{0}}$ and an a priori parameter covariance matrix $C_{m_{0}}$ and solve Eq. (5) by minimizing $(\delta d-G \cdot \delta m)^{T} \cdot C_{d_{0}}^{-1} \cdot(\delta d-G \cdot \delta m)+\delta m^{T} \cdot C_{m_{0}}^{-1} \cdot \delta m$ (e.g., TARANTola and VALETTE, 1982). The superscripts $T$ and -1 denote matrix transpose and inverse, respectively. $C_{d_{0}}$ and $C_{m_{0}}$ are assumed to be diagonal matrices whose elements are the a priori data and parameter variances. We set the a priori standard deviations of the slowness perturbations to $5 \%$, and those of the hypocenter perturbations in the horizontal and vertical directions to 5 and $10 \mathrm{~km}$, respectively. The a priori standard deviations of the origin times and the local station anomalies are set to 1 and $3 \mathrm{~s}$, respectively. The a priori standard errors of the data in the travel time inversion are the same as those assumed in the relocation procedure.

The inversion procedure is non-linear because the partial derivatives $\partial t_{i} / \partial h_{j}^{k}$ depend on the hypocentral locations; we adopt an interative method. We use the ART (Algebraic Reconstruction Technique)-type Bayesian Reconstruction method (ARTB) (Herman, 1980; Hirahara, 1988; Kamiya et al., 1988). The ART-type approaches have the advantage of small memory size and fast computation.

\subsection{Inversion result and resolution}

The travel time inversion converged after nine global iterations. Each global iteration consists of 1,458 ray-by-ray inversions. The variance reduction achieved by the inversion is $64 \%$. Figures $5-7$ show the velocity model and resolution kernels for each of the three cross sections perpendicular to the strike of the Kuril trench shown in Fig. 1. The upper mantle slab has P-wave velocities higher than the surrounding upper mantle. The velocity contrast between the slab interior and the ambient continental mantle is as large as 7\% at depths between 200 and $400 \mathrm{~km}$ and decreases to $4 \%$ in the depth range between 400 and $600 \mathrm{~km}$. The velocity of the continental upper mantle is $2 \%$ lower than the oceanic upper mantle.

We find a slablike high-velocity zone in the lower mantle which extends from 650 to $1,200 \mathrm{~km}$, in depth and has velocities $2-3 \%$ higher than the ambient lower mantle. This high-velocity zones is located along the down-dip extension of the upper mantle Kuril slab. A change of up to $5^{\circ}$ in the dip angle of the upper mantle slab does not influence the dip angle of the lower mantle high-velocity zone.

It is reasonable to suspect that the high-velocity zone derived by the inversion might be an artifact, since the majority of ray paths used in the present study are roughly parallel to the dip of the upper mantle slab. In order to confirm that the high-velocity zone in the lower mantle is not an artifact, we calculate resolving

Fig. 5. The P-wave velocity model obtained by the travel time inversion and a resolving kernel. Cross section along A-A' (Fig. 1) is shown. (a) Velocity profile. Velocity perturbations with respect to the Jeffreys' $\mathrm{P}$-model are represented by figures in the upper mantle and symbols in the lower mantle. Crosses denote higher velocity and circles lower velocity. Symbol size is proportional to the magnitude of the velocity perturbation. (b) Resolving kernel for a target block of a higher velocity. Circle indicates the target block. Integers represent elements of the resolution matrix. All values are multiplied by a factor of 100 . 

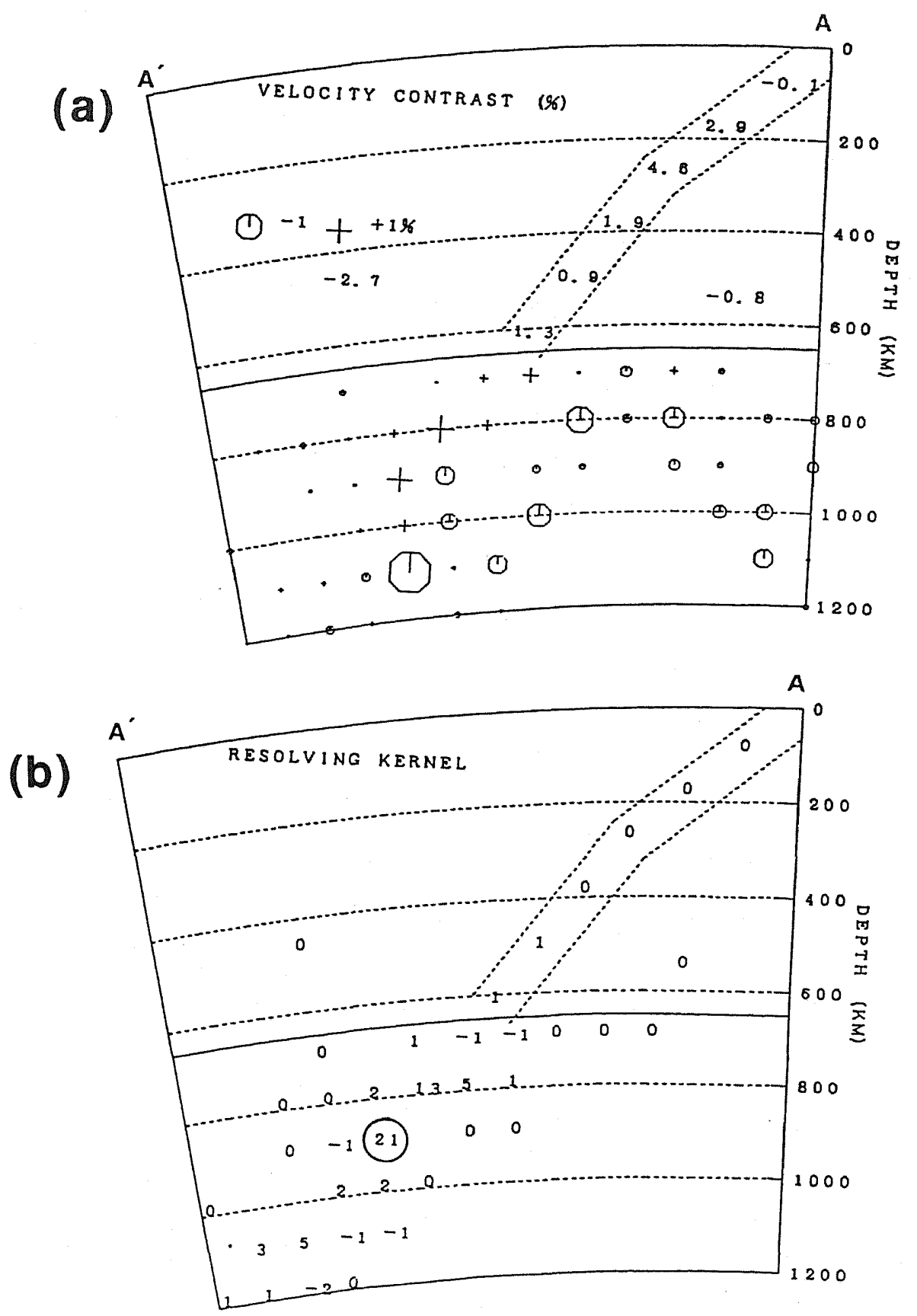

Fig. 5 

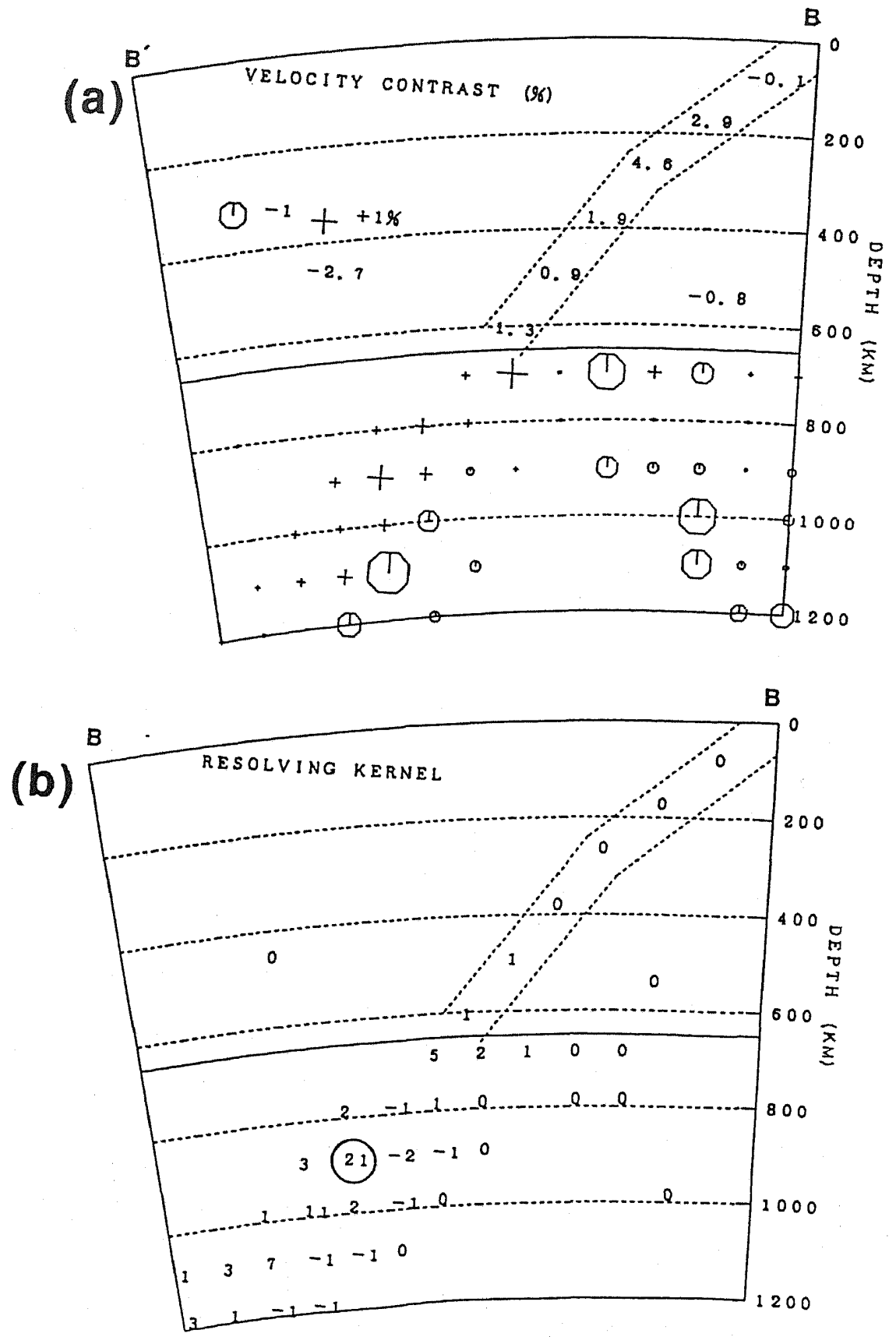

Fig. 6. Same as Fig. 5 but for cross section B-B' (Fig. 1). 

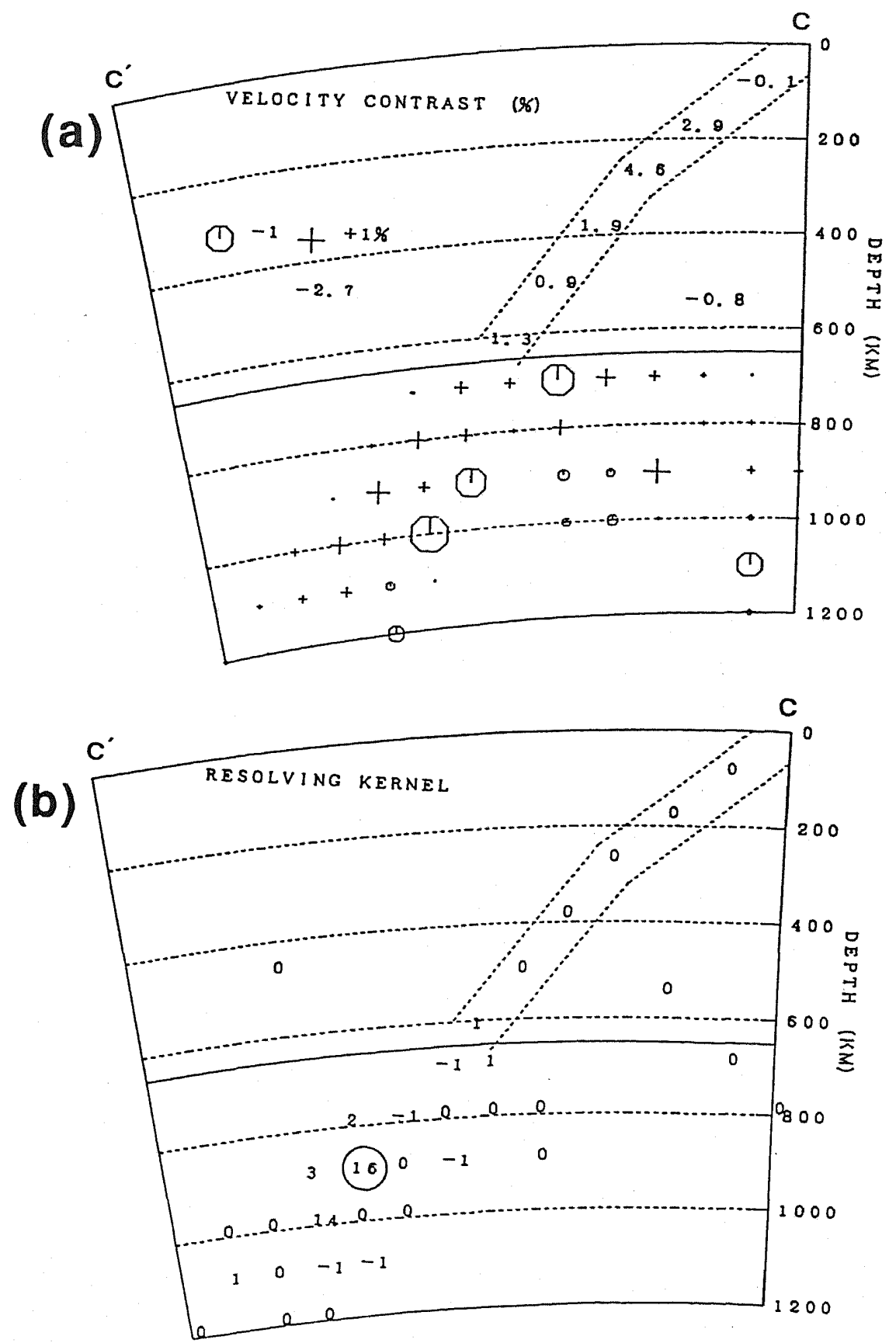

Fig. 7. Same as Fig. 5 but for cross section $\mathrm{C}^{-\mathrm{C}^{\prime}}$ (Fig. 1). 
kernels (WIGGINS, 1972) for velocity perturbations in the lower mantle.

Following HiRAHARA (1988), (1) we construct a trial model in which an anomaly of unit size is assigned to the target parameter and the other parameters are set to zero; (2) we compute travel time residuals with respect to the J-B tables for all of the source-receiver pairs used in the inversion; (3) we invert the travel time residuals in the same manner as described in the previous section. The model obtained from the synthetic data represents the resolving kernel for the target parameter.

Figures 5(b)-7(b) show the resolving kernels for three targets in the high-velocity zone found in the lower mantle. The resolving kernels are elongated in the down-dip direction of the slab, which suggests that the uncertainty of the depth extent of the high-velocity zone in the lower mantle may be as large as $300 \mathrm{~km}$. However, the fact that these kernels have negligible values in the upper mantle implies strongly that the lower mantle high-velocity zone is not an artifact. The resolving kernels also indicate that the location of the oceanic side boundary between the lower mantle high-velocity zone and the ambient lower mantle is well constrained by the data.

The lengths of the relocation vectors relative to the ISC hypocenters are smaller than $2 \mathrm{~km}$ for all the events. This is consistent with the result derived by UTSU (1975) and suggests that errors in the ISC hypocentral locations, which were determined by using both local and teleseismic data, are small for events in the Kuril subduction zone.

The station anomalies determined in this study are in agreement with the results of previous studies. The local station anomalies obtained by the present study have large negative values for SHO, NEM, and KUS $(-1.6,-1.1,-0.8 \mathrm{~s})$ and have large positive values for YSS, UGL, URA, and WAK $(0.9,0.6,0.5$, and $0.4 \mathrm{~s}$ ) (see Fig. 1(a) for the locations of these stations). The anomalies for the other local stations are very small.

Our results are similar to those obtained by the other workers. For example, the station anomaly for YSS estimated by DzIEWONSKI and ANDERSON (1983) is $0.51 \mathrm{~s}$. MAKI (1982) determined average travel time residuals for Japanese stations using teleseismic events. His results were $-1.12 \mathrm{~s}$ for NEM, $-0.50 \mathrm{~s}$ for KUS, $1.00 \mathrm{~s}$ for URA, and $0.86 \mathrm{~s}$ for WAK. The large station corrections obtained by the present study as well as earlier studies suggest that it is essential to incorporate local station corrections into the inversion.

\section{Amplitude Analysis}

Focusing or defocusing of seismic rays by velocity anomalies will generate observable amplitude anomalies. A localized high-velocity anomaly will defocus seismic waves, and thus will cause an amplitude decrease. On the other hand, a low-velocity anomaly will focus seismic waves, leading to an amplitude increase. Amplitudes are more sensitive to the fine structure of velocity anomalies than are travel times, because the former are influenced by the velocity gradient while the 
latter are determined to first order by the velocity itself. Body wave amplitude data can therefore provide us with additional strong constraints on the depth extent and fine structure of the high-velocity zone obtained by the travel time inversion.

Many previous workers have reported observations of the defocusing of teleseismic body waves induced by the lithospheric slab (e.g., Davies and Julian, 1972; SLEEP, 1973; ENGDAHL et al., 1977). Previous studies used events shallower than $150 \mathrm{~km}$ to study the upper mantle slab. Since we intend to determine the lower mantle velocity structure, we must use deeper earthquakes in the present study.

The above studies applied ray tracing techniques to model the slab effects, and succeeded in predicting the locations of observed shadow zones of P-waves by assuming thermal models of the slabs (e.g., Toksöz et al., 1971). The calculated amplitude decrease, however, is much larger than the observed decrease (e.g., SLEEP, 1973). This suggests that the ray-theoretical treatment may be insufficiently accurate for modeling seismic waves in and around the descending slab, since ray theory is applicable only to wave propagation in weakly and continuously heterogeneous media. It is thus necessary to use a wave-theoretical approach.

\section{I P-wave amplitude data}

In this section we analyze $\mathrm{P}$-wave amplitude data from Kuril events with focal depths in the range $130-640 \mathrm{~km}$ to investigate the amplitude anomaly due to aspherical earth structure. In particular, we study whether the lower mantle high-velocity zone obtained from the travel time inversion can explain the observed amplitude anomaly. We compute the theoretical amplitude anomaly using a hybrid method combining a two-dimensional finite element method (FEM) and geometrical ray theory.

We use vertical component records obtained from WWSSN (World-Wide Standardized Seismograph Network) stations. For each event, we choose stations for which the azimuthal deflection from the dip direction of the upper mantle slab is less than $30^{\circ}$, because our two-dimensional calculation method is not accurate when the station azimuth deviates greatly from the dip direction. Figure 8 shows the WWSSN stations used in this study. We select Kuril events deeper than $100 \mathrm{~km}$ during the period from 1964 to 1984 for which P-wave first motions are clearly visible on the SPZ records. The SPZ records are indispensable to the present study, since the amplitude of the short-period waves is much more sensitive to fine velocity structure than the long-period waves. The source parameters of the selected events are listed in Table 2 and the hypocenters are shown in Fig. 9. Since the number of the amplitude data for an individual event is not enough for studying the distance dependence of the amplitude anomaly, we classify the events into three groups according to their focal depths (100-250 km; 400-500 km; 550-650 km) and combine the amplitude data for each of the three depth ranges.

We measure the peak-to-peak amplitude of the first P-motion for the SPZ records and the peak or trough amplitude of the first P-break for the LPZ records, because this portion of the $\mathrm{P}$-waves is least contaminated by source complexities 


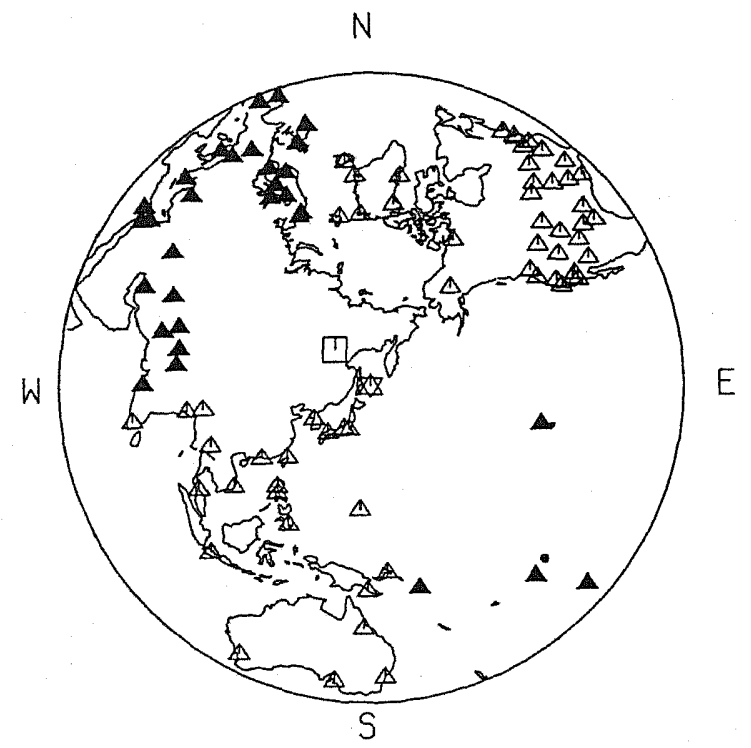

Fig. 8. Equidistant projection centered on the epicenter of the Kuril deep-focus earthquake indicated by the open star. The WWSSN stations are shown by the triangles. Solid triangles are stations used in this study. The open square indicates the pole of the Kuril arc.

and reverberations due to local crustal structures beneath the stations. Examples of the seismograms and the measured portions are shown in Fig. 10.

The teleseismic P-wave amplitude $A_{i j}$ of the $i$-th event at the $j$-th station is expressed by

$$
A_{i j}=I_{j} \cdot S_{j} \cdot G_{i j} \cdot X_{i j} \cdot R_{i j} \cdot M_{i}
$$

where $I_{j}$ denotes the instrument response, $S_{j}$ is the station anomaly, $G_{i j}$ includes the geometrical spreading and the anelastic attenuation factors calculated for a reference earth model, $X_{i j}$ is the amplitude anomaly caused by the aspherical velocity structure, $R_{i j}$ is the radiation pattern at the source, and $M_{i}$ is the scalar factor of the source radiation. We derive $X_{i j}$ from $A_{i j}$ by correcting for the other five factors on the right-hand side of Eq. (6).

The magnification factors range from 3,750 to 400,000 for the WWSSN SPZ data and from 750 to 3,000 for the WWSSN LPZ data. We use these values to correct the observed amplitudes for the instrument response $I_{j}$. We calculate the geometrical spreading factor for the Jeffreys' model using geometrical ray theory. We assume that the effect of the anelastic attenuation on the P-wave amplitude is constant in the teleseismic distances (e.g., CARPENTER, 1966). The correction for the source radiation pattern $R_{i j}$ is made by using the double couple solutions given by previous studies. We eliminate amplitude data for which the radiation corrections 


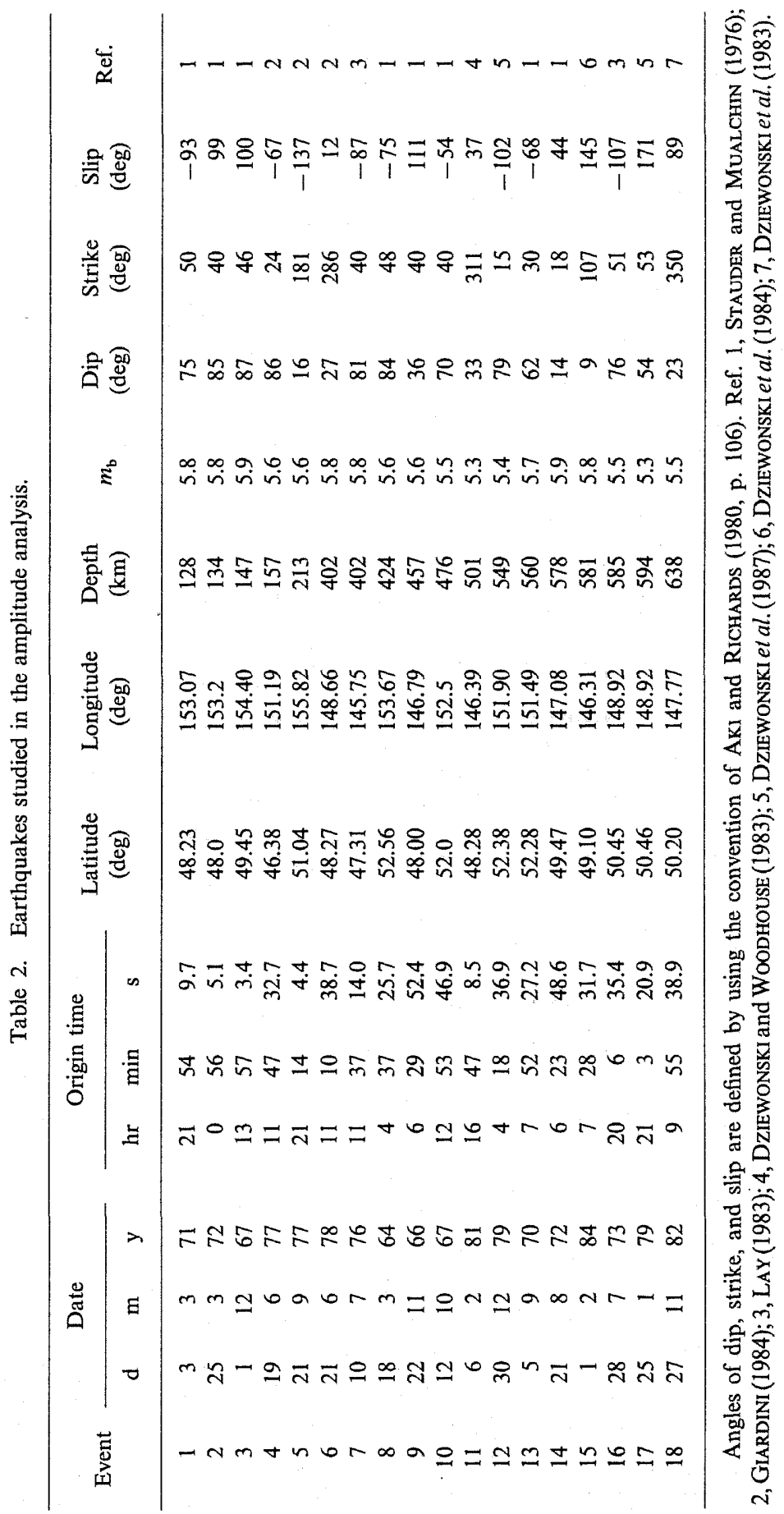


(a)

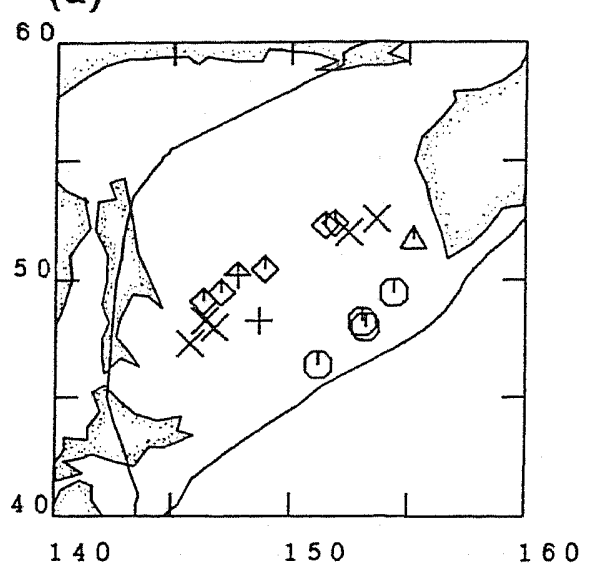

(b)

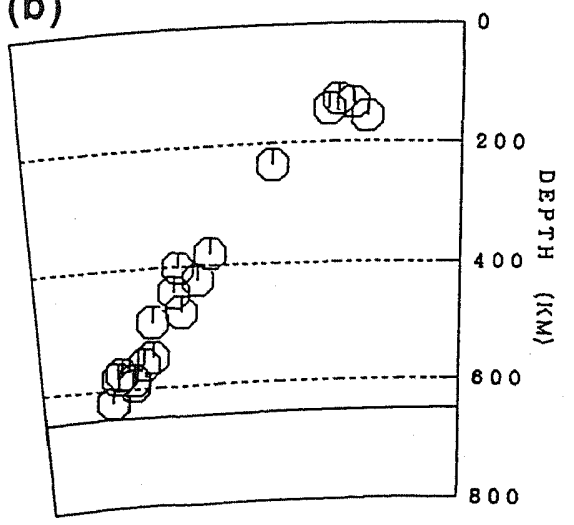

Fig. 9. Hypocenters of the earthquakes used in the amplitude analysis. (a) Epicenters. Symbol convention is the same as in Fig. 1. (b) Hypocenters projected onto a cross section taken perpendicular to the strike of the Kuril arc.

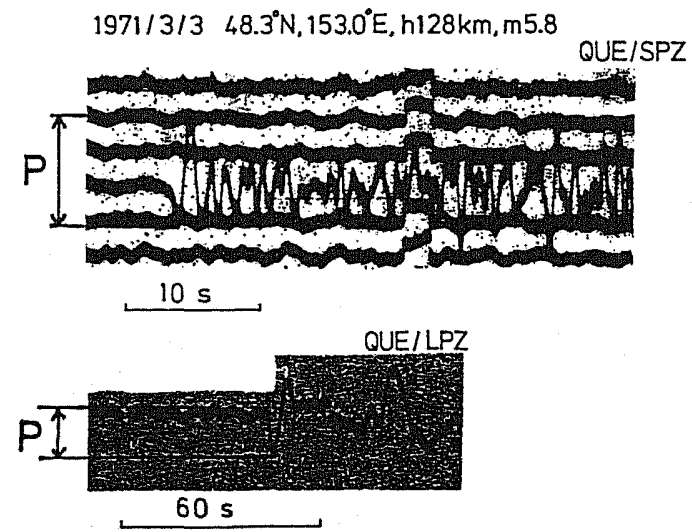

Fig. 10. Examples of the WWSSN seismograms used in this study. The measured portions in the seismograms are indicated in the figure.

are larger than a factor of 5 , to avoid data near the nodal planes. Since in the present study we use the composite amplitude data for the each of the three depth ranges, we must correct the amplitude data for the scalar source factor $M_{i}$. We normalize the amplitude data from each event so that the average amplitude for oceanic stations is equal to unity. The oceanic data are probably free of the Kuril slab effect because P-waves traveling toward the oceanic stations exit the Kuril slab rapidly, so they provide an appropriate reference datum. We correct the amplitude data for the station anomaly $S_{j}$ using the SENGUPTA's (1975) table of short- and 
long-period amplitude station corrections. The station corrections were determined using teleseismic body wave amplitude data from deep events in subduction zones over the world and range from -2.0 to +2.2 on a $\log _{2}$-scale for the short-period amplitude and from -1.1 to +1.0 for the long-period amplitude.

To determine whether the amplitude anomaly due to near-source heterogeneous structure can be derived from the WWSSN data, we analyze the amplitude data for the events shallower than $250 \mathrm{~km}$, since the Kuril slab should induce defocusing of the teleseismic P-waves for the intermediate events. Figure 11(a) shows the normalized short-period amplitude anomalies $\left(X_{i j}\right.$ in Eq. (6)) at continental stations for events in the depth range $100-250 \mathrm{~km}$. Since the scatter in the amplitude data is large, we average the values for each $5^{\circ}$-interval of epicentral distance and we express the results in terms of the $\log _{2}$ of the amplitude anomaly. The amplitudes are a factor of 2 smaller at distances between $55^{\circ}$ and $65^{\circ}$ than the average amplitude of the oceanic stations. We interpret this amplitude reduction as the defocusing effect due to the Kuril slab and conclude that the WWSSN amplitudes are useful for studying the near-source heterogeneous structure.

The above result encourages us to analyze amplitude data for the deep events to determine the heterogeneous structure of the lower mantle. Figures 11(b) and (c) show the short-period amplitude anomalies for events in the depth ranges of $400-500 \mathrm{~km}$ and $550-650 \mathrm{~km}$, respectively. The amplitude anomalies are as large as $-1--1.5$ in the distances between $50^{\circ}$ and $65^{\circ}$. The distance range from $50^{\circ}$ to $65^{\circ}$ corresponds to takeoff angles ranging from $46^{\circ}$ to $38^{\circ}$ from vertical for events with focal depths $550-650 \mathrm{~km}$. This range of takeoff angles is roughly equal to the $40^{\circ}$ dip angle of the lower mantle high-velocity zone obtained by the travel time inversion (Figs. 5-7). This coincidence suggests that the lower mantle high-velocity zone is responsible for the amplitude decrease.

We also calculate the long-period $\mathrm{P}$-wave amplitude anomaly in the same way as the short-period amplitude anomaly, since the frequency dependence of the amplitude anomaly may help to constrain the near-source velocity structure. Figure 12 shows that the long-period amplitude is almost constant in the distance range $55^{\circ}-85^{\circ}$ for all the depth ranges.

\subsection{Method for calculating theoretical amplitudes}

We devise a numerical method for modeling teleseismic $\mathbf{P}$-wave amplitudes for a source located in a laterally heterogeneous medium. Our method has two steps: (1) We apply an FEM scheme to calculate the displacement field in the heterogeneous near-source region; (2) The amplitudes of the P-waves in the near-source region are extrapolated to teleseismic distances using geometrical ray theory for a spherically symmetric velocity structure.

On the basis of the travel time inversion, we assume that the lower mantle high-velocity zone is located in the rectangular region shown in Fig. 13. We use the FEM to calculate the wave field in this region. We divide the FEM domain into triangular elements of an equal size, and use Galerkin's principle for the 

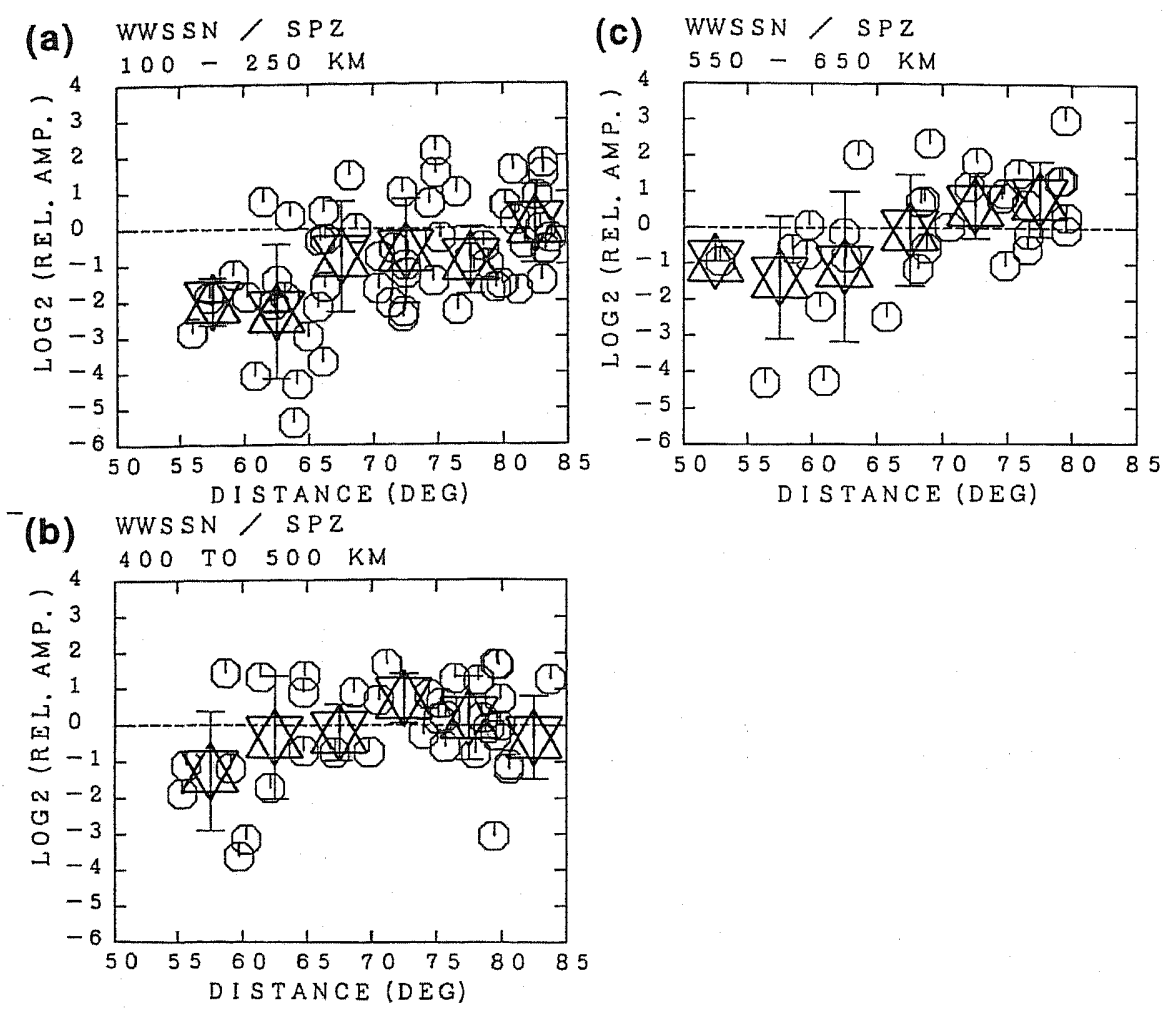

Fig. 11. Amplitude anomalies on a $\log _{2}$-scale for the short-period $\mathrm{P}$-waves. Open circles are individual amplitude anomalies. Solid stars indicate the average of the amplitude anomalies within a $5^{\circ}$ distance window. (a) Amplitude anomalies for events with depths ranging from $100-250 \mathrm{~km}$. (b) $400-$ $500 \mathrm{~km}$. (c) $550-650 \mathrm{~km}$.

two-dimensional elastodynamic equation to derive the two-dimensional FEM equation (e.g., ZIENKIEWICZ, 1977).

We follow the method of SMITH (1974) to eliminate artificial reflections from the boundary of the numerical grid for a sufficiently long interval. The elastic waves are excited by applying an isotropic source to the nodes on the top of the FEM domain (Fig. 13). The time-dependent part of the applied force is a full-cycle sine with a period of $1.5 \mathrm{~s}$ for the WWSSN short-period records and $10 \mathrm{~s}$ for the WWSSN long-period records. Based on the conditions for the accuracy of the FEM solution (e.g., SMITH, 1975) and the available size of computer memory, we select mesh sizes

Fig. 13. Schematic illustration of the FEM domain. Dotted lines delineate the boundaries of the FEM domain, solid lines are boundaries of the high-velocity zone. An isotropic source is on the upper boundary of the FEM domain. 

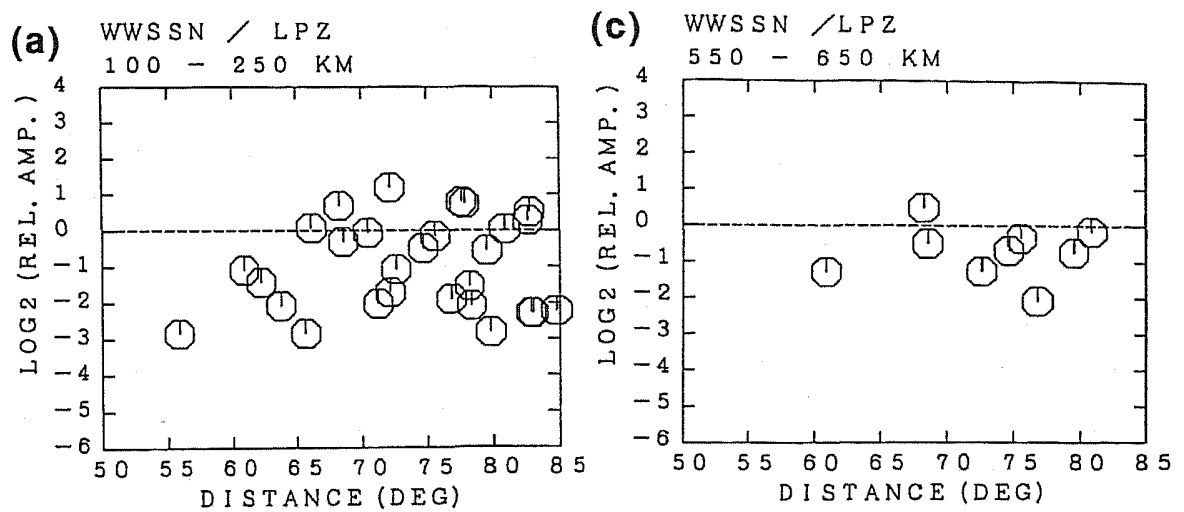

(b) WWSSN $\angle P Z$

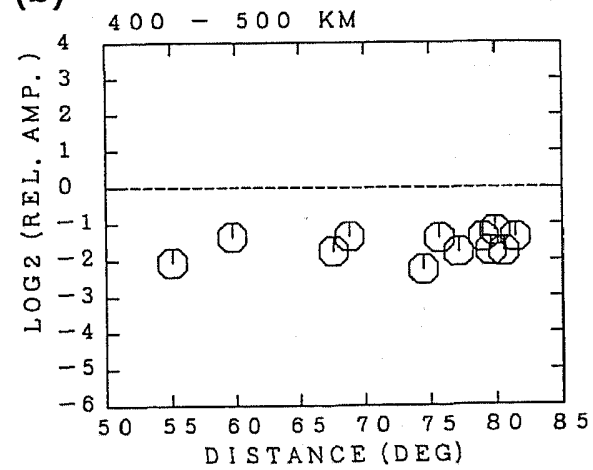

Fig. 12. Amplitude anomalies for the long-period P-waves. Symbol convention is the same as in Fig. 11. (a) Amplitude anomalies for the events with depths ranging from $100-250 \mathrm{~km}$. (b) $400-500 \mathrm{~km}$. (c) $550-650 \mathrm{~km}$.
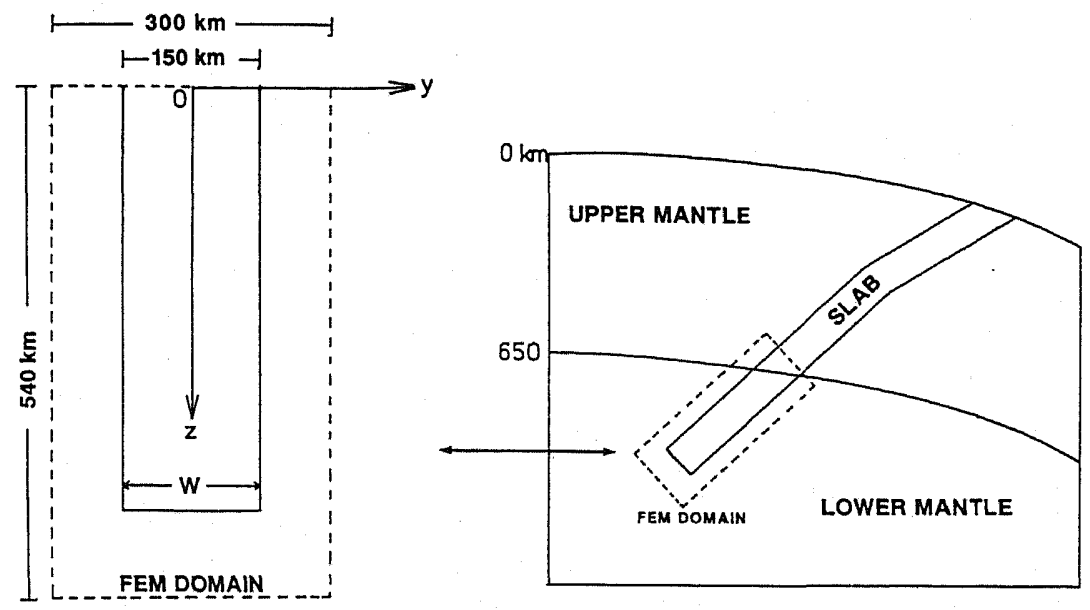

Fig. 13 
of 1.2 and $5 \mathrm{~km}$ for periods of 1.5 and $10 \mathrm{~s}$, respectively.

We extrapolate the P-wave amplitudes from the boundary of the FEM domain to teleseismic distance using ray tracing. For a ray with a takeoff angle $i$ (with respect to vertical) which leaves a node on the FEM boundary at depth $r$, we trace the ray to the earth's surface to obtain the geometrical spreading factor $G$

$$
G(i)=\sqrt{\frac{\alpha_{r} \rho_{r} \sin i}{\alpha_{0} \rho_{0} a^{2} \sin \Delta_{1} \cos i_{0}}}\left|\frac{d i}{d \Delta_{1}}\right|
$$

where $\alpha$ and $\rho$ are the P-wave velocity and density, respectively. The subscripts $r$ and 0 indicate the depth $r$ and the Earth's surface, respectively, and $a$ is the Earth's radius. The angular distance $\Delta_{1}$ between the node and the end point of the ray at the Earth's surface and $d i / d \Delta_{1}$ are calculated by ray tracing (e.g., JuLIAN, 1970). The teleseismic P-wave amplitude $A_{\text {tel }}$ is the product of the near-source amplitude at the node $A_{f e m}$ and the geometrical spreading factor $G(i)$ :

$$
A_{\text {tel }}(\Delta)=G(i) \cdot A_{\text {fem }}
$$

where

$$
\Delta=\Delta_{1}+\Delta_{2}
$$

$\Delta_{2}$ denotes the angular distance between the source and the node on the FEM boundaries and $\Delta$ is the epicentral distance. The takeoff angle $i$ is determined from the polarization of the first half-cycle of the P-motion at the node. We calculate $A_{\text {tel }}$ for each node on the FEM boundary and interpolate to obtain the amplitude at an arbitrary epicentral distance.

\subsection{Comparison between observed and theoretical amplitude}

To determine whether the lower mantle high-velocity zone is responsible for the observed amplitude anomaly, we compare the theoretical and the observed amplitude anomalies. We consider only events in the depth range from 550 to $650 \mathrm{~km}$, because the computer storage required to calculate the theoretical amplitudes for the shallower events is too large to be tractable for the currently available computer systems.

We characterize the velocity model of the dipping high-velocity zone using three parameters: (1) maximum depth; (2) velocity distribution; and (3) thickness. These parameters could not be well resolved by the travel time inversion in the present study. Table 3 shows the values of these parameters for the various models used in our study. We change the velocity contrast along with the maximum depth to obtain travel time anomalies of about $-1.5 \mathrm{~s}$, which were observed in the present study: $+3.5 \%$ for the maximum depth of $1,000 \mathrm{~km}$ and $+6 \%$ for the depth of $800 \mathrm{~km}$. We parameterize the velocity distribution in the high-velocity zone by $W_{1} / W_{2}$, where $W_{1} / W_{2}$ specifies the location of the peak velocity in the high-velocity zone. $W_{1}$ is the distance between the peak velocity and the upper (continental-side) boundary of the high-velocity zone and $W_{2}$ is the distance between the peak velocity 
Table 3. Parameters of the high-velocity zone adopted in the present study.

\begin{tabular}{ll}
\hline Velocity structure & $\begin{array}{r}\text { Model A }\left(W_{1} / W_{2}=1.00\right) \\
\text { Model B }\left(W_{1} / W_{2}=0.18\right) \\
\text { Model C }\left(W_{1} / W_{2}=5.67\right)\end{array}$ \\
\hline Maximum depth & $\begin{array}{r}1,000 \mathrm{~km} \text { (Velocity contrast }=3.5 \%) \\
800 \mathrm{~km} \text { (Velocity contrast }=6.0 \%)\end{array}$ \\
\hline Thickness & $150 \mathrm{~km} ; 250 \mathrm{~km}$ \\
\hline
\end{tabular}

For details see text and Fig. 14.
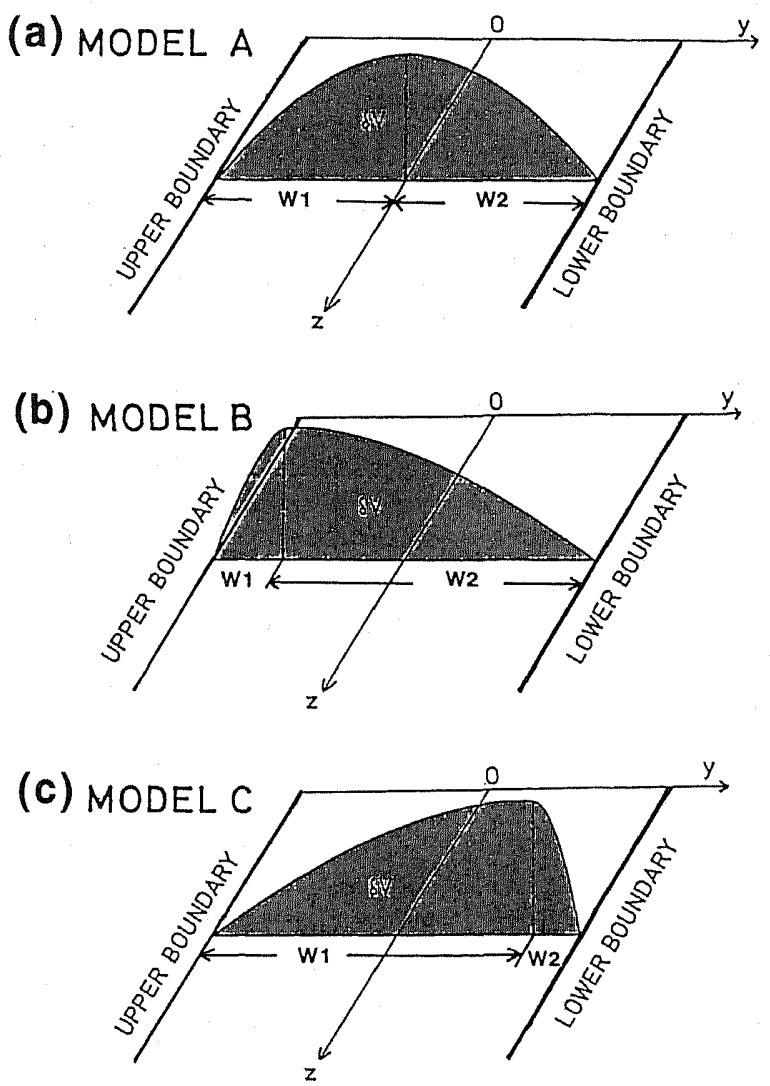

Fig, 14. Schematic illustrations of the trial velocity models. See text for details. (a) Velocity model A. (b) Model B. (c) Model C. $W_{1} / W_{2}=$ $1.00,0.18$, and 5.67 for models $\mathrm{A}, \mathrm{B}$, and $\mathrm{C}$, respectively. 
and the lower (oceanic-side) boundary (Fig. 14). Figure 14 shows the velocity distributions for the three models that we test in the present study.

Since we use observed amplitude data for several Kuril deep sources, we allow for small differences in the hypocenters by calculating theoretical amplitude anomalies for three hypocenters: (a) at a depth of $600 \mathrm{~km}$ on the central axis of the Kuril slab; (b) at a depth of $580 \mathrm{~km}, 30 \mathrm{~km}$ from the central axis towards the upper boundary of the Kuril slab; and (c) at a depth of $620 \mathrm{~km}, 30 \mathrm{~km}$ from the central axis towards the lower boundary. We then compare the composite theoretical amplitude anomalies for the three sources to the observed anomalies.

First, we study whether the high-velocity zone obtained by the travel time inversion can explain the large amplitude reduction observed for short-period $\mathrm{P}$-waves in the present study. We calculate the defocusing for velocity models $\mathrm{A}$, $\mathrm{B}$, and $\mathrm{C}$. In this experiment, we set the maximum depth and the thickness to $1,000 \mathrm{~km}$ and $150 \mathrm{~km}$, respectively; these values are consistent with the results of the travel time inversion but cannot be determined from the travel time data alone. Figures 15(a)-(c) indicate that the high-velocity zone that is present in each of the velocity models can produce defocusing with a magnitude comparable to the observed amplitude reduction. This suggests that a high-velocity zone is responsible for the observed amplitude reduction.

We determine the parameters of the high-velocity zone which gives the best fit to the observed amplitudes of the short-period P-waves. Because Figs. 15(a)-(c) show that the velocity distribution in the high-velocity zone is the most dominant factor controlling the distance dependence of the amplitudes, we determine the velocity distribution first. We conclude from Figs. 15(a)-(c) that model B is the most appropriate velocity distribution for explaining the distance dependence of the observed amplitude; hence we adopt model B hereinafter.

Determining the values of the other two parameters is much more difficult than determining the velocity distribution. In order to determine the maximum depth, we calculate the amplitude anomalies for maximum depths of 800 and $1,000 \mathrm{~km}$ and compare them to the observed amplitude anomalies. In this calculation,

Fig. 15. Comparison between the theoretical and the observed short-period amplitudes (stars) for the events with focal depths $550-650 \mathrm{~km}$. Shaded zone indicates a range of theoretical amplitude calculated from the three source locations: a hypocenter on the central axis of the Kuril slab (solid circles); a hypocenter at $30 \mathrm{~km}$ towards the upper boundary of the slab from the central axis (upward-pointing triangles); a hypocenter at $30 \mathrm{~km}$ towards the lower boundary of the slab from the central axis (downward-pointing triangles). (a) Velocity model $\mathrm{A}$. The maximum depth and the thickness of the high-velocity zone are $1,000 \mathrm{~km}$ and $150 \mathrm{~km}$, respectively. (b) Velocity model B, the depth of $1,000 \mathrm{~km}$, and the thickness of $150 \mathrm{~km}$. (c) Velocity model C, the depth of $1,000 \mathrm{~km}$, and the thickness of $150 \mathrm{~km}$. (d) Velocity model B, the depth of $800 \mathrm{~km}$, and the thickness of $150 \mathrm{~km}$. (e) Velocity model B, the depth of $1,000 \mathrm{~km}$, and the thickness of $250 \mathrm{~km}$. 
(a) WWSSN $/ \mathrm{SPZ}$

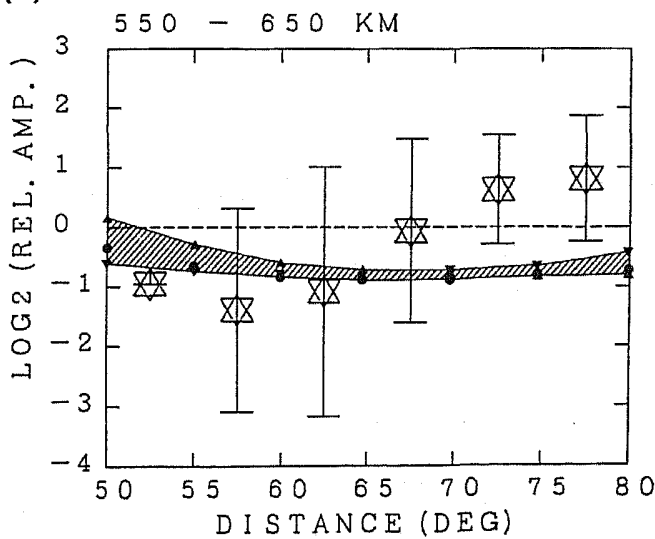

(b) WWSSN $/ \mathrm{SPZ}$

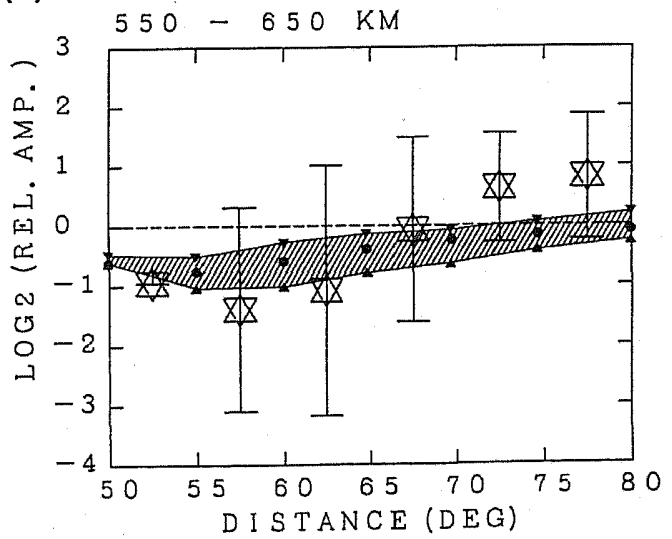

(c) WWSSN $/ \mathrm{SPZ}$

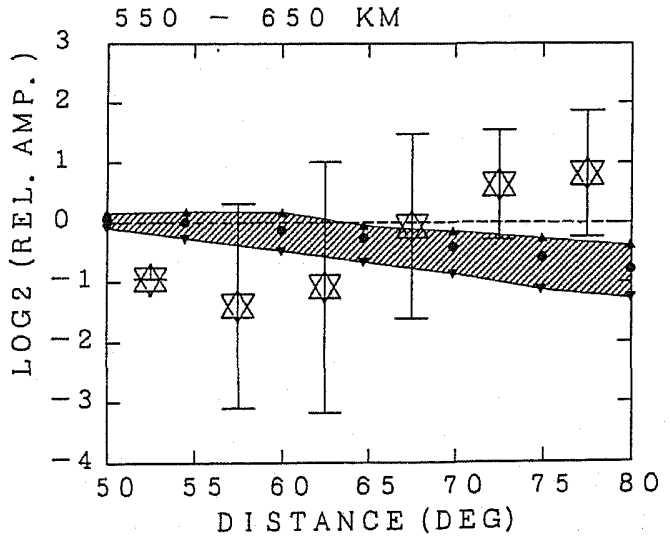

(d) WWSSN $/ \mathrm{SPZ}$

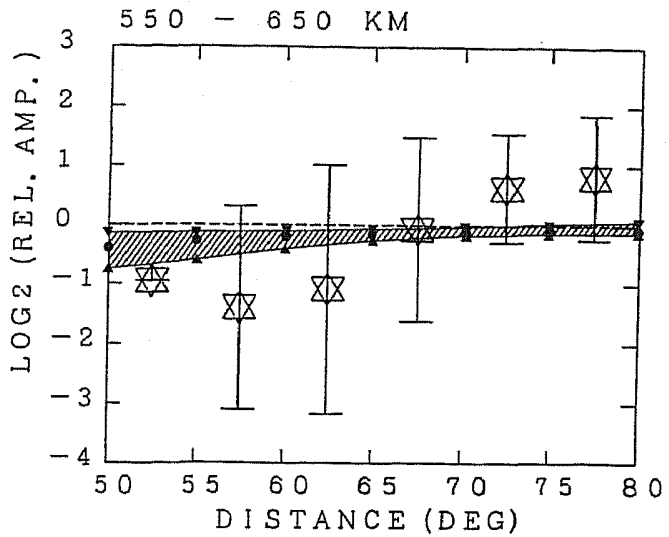

(e) WWSSN $/ \mathrm{SPZ}$

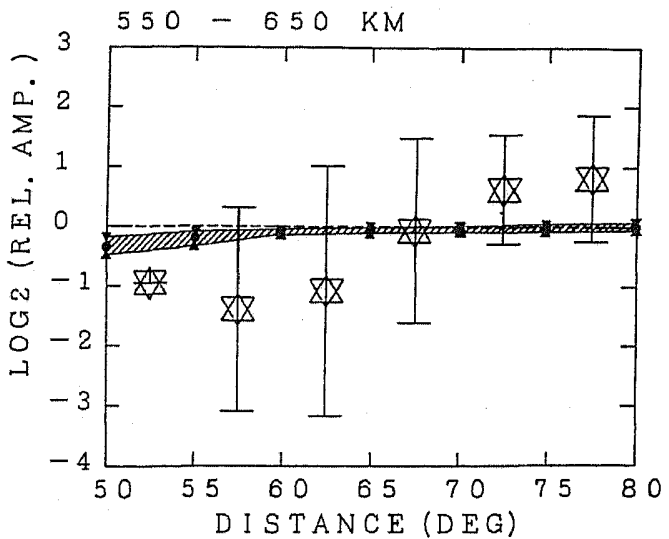

Fig. 15 


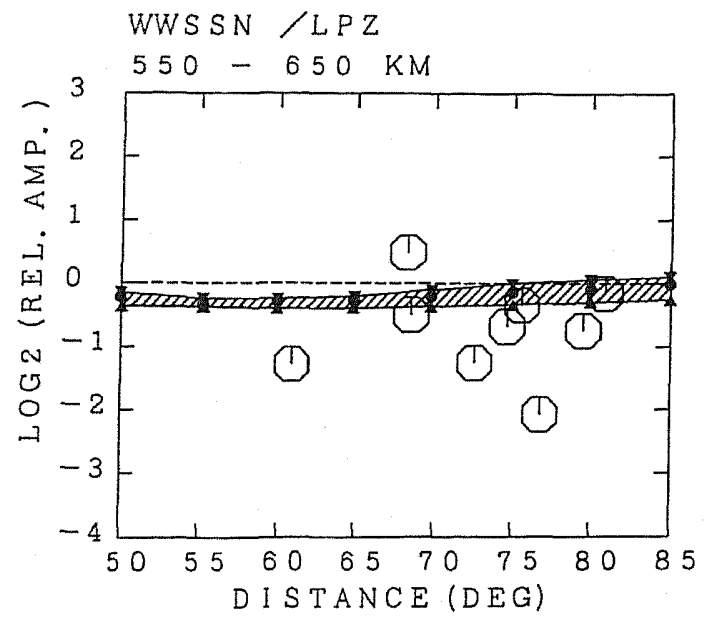

Fig. 16. Comparison between the theoretical and the observed long-period amplitudes for the events with focal depths $550-650 \mathrm{~km}$. Symbol conventions are the same as in Fig. 15. Velocity model B, the maximum depth and the thickness of the high-velocity zone are $1,000 \mathrm{~km}$ and $150 \mathrm{~km}$, respectively.

we fix the thickness to $150 \mathrm{~km}$. Figures 15 (b) and (d) show that a maximum depth of $1,000 \mathrm{~km}$ provides a slightly better fit to the data than a maximum depth of $800 \mathrm{~km}$. We then change the thickness of 150 to $250 \mathrm{~km}$ with the maximum depth fixed to $1,000 \mathrm{~km}$. As shown in Fig. 15(e), a thickness of $250 \mathrm{~km}$ provides amplitude anomalies which are too small to explain the overall magnitude of the observed amplitude anomalies. However, the scatter of the data is so large that all of the theoretical amplitude anomalies for the various values of the maximum depth and the thickness lie within the error bars of the data. We thus conclude that a high-velocity zone of model B can explain the short-period amplitude data. We tentatively adopt a maximum depth of $1,000 \mathrm{~km}$ and a thickness of $150 \mathrm{~km}$ for the high-velocity zone.

We also compare theoretical and observed amplitude anomalies for the long-period data (Fig. 16). We calculate the theoretical amplitudes using the velocity model determined above for the short-period amplitude data. As shown in Fig. 16, both the theoretical and observed amplitude anomalies are weak and consistent with each other. However, the long-period data do not enable us to determine the above three parameters of the lower mantle high-velocity zone, since the theoretical amplitude anomalies for the long-period P-waves are very small regardless of the velocity model adopted for the high-velocity zone.

We cannot determine the event location which gives the best fit to the data in the present study, since we use composite amplitude data for several events with hypocenters different from each other. We must analyze a large number of amplitude data from a single event to study the location of the deep event in the interior of the slab. 
In conclusion, the lower mantle high-velocity zone in the down-dip direction of the Kuril slab, which was obtained by the travel time inversion, provides adequate fits to the observed amplitude anomalies. The velocity gradient near the upper boundary of the high-velocity zone is larger than that near the lower boundary. The maximum depth, the thickness, and velocity contrast of the high-velocity zone are $1,000 \mathrm{~km}, 150 \mathrm{~km}$, and $3.5 \%$, respectively. However, the large scatter in the amplitude data prevents us from precisely determining the maximum depth and thickness of the high-velocity zone.

\section{Discussion and Conclusions}

In the present study, we have assumed that near-source heterogeneity is responsible for both the observed travel time and amplitude anomalies and have concluded that the high-velocity zone immediately under the Kuril deep sources explains the observed travel time and amplitude anomalies. We show from the observed amplitude anomaly (i.e., defocusing) that the above assumption is correct, using the fact that defocusing is controlled by the velocity gradient along the ray path. We show the theoretical defocusing due to high-velocity zones with velocity gradients of about $(0.07 \mathrm{~km} / \mathrm{s}) / 150 \mathrm{~km}$ and $(0.07 \mathrm{~km} / \mathrm{s}) / 250 \mathrm{~km}$ in Figs. $15(\mathrm{~b})$ and (e), respectively. Figures 15 (b) and (e) indicate that the smaller velocity gradient gives the weaker defocusing. We cannot attribute the observed large defocusing to lateral heterogeneity far from the Kuril sources: if the laterally heterogeneous region is located far from the source region, the size of the heterogeneous region must be extremely large to explain the distance range $\left(50^{\circ}-65^{\circ}\right)$ over which the defocusing is observed (Fig. 17); thus the velocity gradient in the heterogeneous region would be too small to produce observable defocusing. We therefore conclude that the lateral heterogeneity is located in the lower mantle immediately under the Kuril deep source region.

We have not taken into consideration lateral heterogeneity of anelastic attenuation $(Q)$ in the present study. We study whether the incorporation of the lateral heterogeneity of $Q$ in the amplitude calculation will significantly change our conclusions on the lower mantle structure, since the velocity heterogeneity may be accompanied with the $Q$ heterogeneity. In order to evaluate the maximum effect of the $Q$ heterogeneity on the amplitude anomaly, we calculate the amplitude ratio of a ray traveling entirely in the high- $V$, high- $Q$ zone to a ray traveling in the normal mantle, assuming that $Q$ in the high-velocity zone is 10 times as high as that of the normal mantle. Ray theoretical evaluation of the attenuation is given by $\exp \left(-\omega L / 2 V_{a v} Q_{a v}\right)$ where $V_{a v}$ and $Q_{a v}$ denote velocity and $Q$ averaged along the ray path, respectively, and $L$ is the propagation distance. We adopt the $Q$ model SL8 (ANDERSON and HART, 1978) and Jeffreys' P-velocity model to the normal mantle. These models give $Q_{a v}=614$ and $V_{a v}=10.8 \mathrm{~km} / \mathrm{s}$ as the average values in the depth range from 600 to $1,000 \mathrm{~km}$. Adopting $L=500 \mathrm{~km}$, the amplitude ratios are $0.86\left(-0.22\right.$ on $\log _{2}$-scale) for the short-period and $0.98(-0.03)$ for the long-period. 


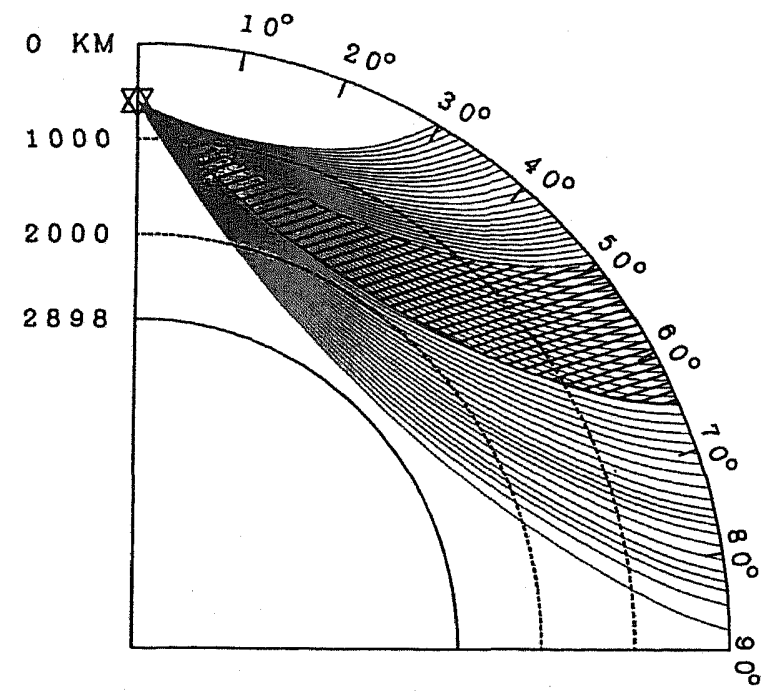

Fig. 17. Cross section of the earth illustrating possible region of high-velocity anomaly (shaded area). Ray paths from a source at a depth of $600 \mathrm{~km}$ to teleseismic distances are also shown.

The effect of the $Q$ heterogeneity on the amplitude anomaly is thus so small that we need not change our conclusions on the lower mantle high-velocity zone.

We compare the velocity structure in the upper mantle slab to the lower mantle high-velocity zone. Our amplitude analysis indicates that a lower mantle high-velocity zone with a steep velocity gradient near the upper boundary and a gentle gradient near the lower boundary provides the best fit to the observations. For the upper mantle slabs, many previous studies found a large velocity gradient or discontinuity near the upper boundary of the descending slabs based on either phase conversions (OKADA, 1971; SNOKE et al., 1977; MATSUZAWA et al., 1986), or reflections of body waves at the upper boundary (FUKAO et al., 1978; STEFANI et al., 1982). On the other hand, body waves converted or reflected at the lower plate boundary have not generally been reported. This suggests that the upper mantle slab has a velocity gradient which is much larger in the vicinity of the upper boundary than the lower boundary and has a velocity structure similar to the lower mantle high-velocity zone obtained in the pesent study.

JORDAN (1977) and CREAGER and JORDAN $(1984,1986)$ studied the lower mantle structure under the Kurils using body wave arrival time data and concluded that the lithospheric slab penetrates into the lower mantle. However, they claimed that the dip of the Kuril slab changes at a depth of about $500 \mathrm{~km}$ from $50^{\circ}$ to $70^{\circ}$ or more. In the present study, there is no dip change: the lower mantle high-velocity zone extends in the down-dip direction of the upper mantle slab. Recently MrYATAKE and HIraHaRA (1989) applied tomographic inversion to a large number of ISC P-arrival time data to determine the mantle structure beneath the Japan and the 
Kurils, and showed that the lower mantle high-velocity zone extends straight into the lower mantle. We conclude that our present result for the dip of the high-velocity zone is correct, because high-velocity zones with dip angles larger than that found by the present study would produce defocusing effects at distances greater than those observed in the present study, and would not provide an adequate fit to the observed amplitude anomalies.

A plausible interpretation for the lower mantle high-velocity zone is lithospheric slab penetration into the lower mantle. The slab penetration hypothesis implies a large flux of mantle material across the $650 \mathrm{~km}$ discontinuity. An alternative interpretation is that the lower mantle high-velocity zone is a cold body cooled by the upper mantle slab through thermal coupling between the upper and lower mantle (e.g., HondA, 1988). The latter interpretation does not require any mass flux across the $650 \mathrm{~km}$ discontinuity. The similarity in the velocity structure and absence of dip change between the lower mantle high-velocity zone and the upper mantle slab tend to favor the slab penetration hypothesis, but further studies are required.

The large scatter in our amplitude data prevents us from precisely determining the depth extent and thickness of the lower mantle high-velocity zone. Data from well calibrated digital seismographs with high-dynamic range will probably improve the depth resolution, although current digital seismographs are not distributed densely enough to detect the slab effect on body wave amplitude. World-wide deployment of the digital seismographs has recently been started by the FDSN (Federation of Digital Broadband Seismograph Networks) (RomanowICZ, 1986). High-quality data with dense station coverage, which will be available in the near future, are highly desirable to determine the lower mantle structure underneath the subduction zone and definitively understand the fate of the lithospheric slab.

I am grateful to Ichiro Nakanishi who constantly encouraged me and gave me valuable comments. I would like to thank Bob Geller for critically reviewing the manuscript and helpful discussions. I also thank Hiroshi Okada, Takeo Moriya, Yasunori Nishida, Tsutomu Sasatani, and Hideki Shimamura for their valuable advice and discussions. This work is a part of my Sc. D thesis at Hokkaido University. This work was partially supported by grants from the Ministry of Education, Science and Culture of Japan (Nos. 62540285 and 63790192). The computations were made on HITAC M680H and $\mathrm{S} 810$ at the Hokkaido University Computing Center and HITAC S820 at the Computing Center of the University of Tokyo.

\section{REFERENCES}

AKI, K. and P. G. RICHARDS, Quantitative Seismology, Vol. I, W. H. Freeman and Company, San Francisco, 1980.

Anderson, D. L. and R. S. HART, $Q$ of the earth, J. Geophys. Res., 83, 5869-5882, 1978.

BECK, S. L. and T. LAY, Test of the lower mantle slab penetration hypothesis using broadband S waves, Geophys. Res. Lett., 13, 1007-1010, 1986.

Carpenter, E. W., A quantitative evaluation of teleseismic explosion records, Proc. R. Soc. London, A, 290, 396-407, 1966. 
CORMIER, V. F., Slab diffraction of S waves, J. Geophys. Res., 94, 3006-3024, 1989.

Creager, K. C. and T. H. Jordan, Slab penetration into the lower mantle, J. Geophys. Res., 89, 3031-3049, 1984.

Creager, K. C. and T. H. Jordan, Slab penetration into the lower mantle beneath the Mariana and other island arcs of the northwest Pacific, J. Geophys. Res., 91, 3573-3589, 1986.

Davies, D. and B. R. Julian, A study of short period P-wave signals from Longshot, Geophys. J. R. Astron. Soc., 29, 185-202, 1972.

Davies, D. and D. P. McKenzie, Seismic travel-time residuals and plates, Geophys. $J . R$. Astron. Soc., 18, 51-63, 1969.

DzIEwONSKI, A. M. and D. L. ANDERson, Travel times and station corrections for P waves at teleseismic distances, J. Geophys. Res., 88, 3295-3314, 1983.

DzIEWONSKI, A. M. and F. GILBERT, The effect of small, aspherical perturbations on travel times and a re-examination of the corrections for ellipticity, Geophys. J. R. Astron. Soc., 44, 7-17, 1976.

DzIEWonski, A. M. and J. H. Woodhouse, An experiment in systematic study of global seismicity: Centroid-moment tensor solutions for 201 moderate and large earthquakes of 1981, J. Geophys. Res., 88, 3247-3271, 1983.

Dziewonski, A. M., J. E. Franzen, and J. H. Woodhouse, Centroid-moment tensor solutions for January-March, 1984, Phys. Earth Planet. Inter., 34, 209-219, 1984.

Dziewonski, A. M., G. Ekström, J. E. Franzen, and J. H. Woodhouse, Global seismicity of 1979: Centroid-moment tensor solutions for 524 earthquakes, Phys. Earth Planet. Inter., 48, 18-46, 1987.

Dziewonski, A. M., A. Friedman, D. Giardini, and J. H. Woodhouse, Global seismicity of 1982: Centroid-moment tensor solutions for 308 earthquakes, Phys. Earth Planet. Inter., 33, 76-90, 1983.

ENGDahl, E. R., N. H. SLEEP, and M.-T. LiN, Plate effects in North Pacific subduction zones, Tectonophysics, 37, 95-116, 1977.

FisCHER, K. M., T. H. JORDAN, and K. C. CREAGER, Seismic constraints on the morphology of deep slabs, J. Geophys. Res., 93, 4773-4783, 1988.

FukaO, Y., K. Kanso, and I. NaKamuRA, Deep seismic zone as an upper mantle reflector of body waves, Nature, 272, 606-608, 1978.

GIardiNI, D., Systematic analysis of deep seismicity: 200 centroid-moment tensor solutions for earthquakes between 1977 and 1980, Geophys. J. R. Astron. Soc., 77, 883-914, 1984.

HeRman, G. T., Image Reconstruction from Projections: The Fundamentals of Computerized Tomography, Academic Press, New York, 1980.

Hirahara, K., Detection of three-dimensional velocity anisotropy, Phys. Earth Planet. Inter., 51, 71-85, 1988.

HONDA, S., Two-layer convection with a soft boundary-Slab penetration and mantle convection-, Zisin, 40, 575-592, 1988 (in Japanese with English abstract).

Jefrreys, H. and K. E. Bullen, Seismological Tables, British Association for the Advancement of Science, Gray-Milne Trust, 1940.

JORDAN, T. H., Lithospheric slab penetration into the lower mantle beneath the Sea of Okhotsk, J. Geophys., 43, 473-496, 1977.

JULIAN, B. R., Ray tracing in arbitrarily heterogeneous media, Technical Note 1970-45, Lincoln Lab., Cambridge, Mass., 1-17, 1970. 
Kamiya, S., T. Miyatake, and K. Hirahara, How deep can we see the high velocity anomalies beneath the Japan Islands?, Geophys. Res. Lett., 15, 828-831, 1988.

LAY, T., Localized velocity anomalies in the lower mantle, Geophys. J. R. Astron. Soc., 72, 483-516, 1983.

MAKI, T., Residuals of teleseismic P-wave travel times observed in Japan, Bull. Earthq. Res. Inst. Univ. Tokyo, 57, 151-191, 1982.

MatsuzaWA, T., N. Umino, A. HasegaWA, and A. TAKagi, Upper mantle velocity structure estimated from PS-converted wave beneath the north-eastern Japan Arc, Geophys. $J$. R. Astron. Soc., 86, 767-787, 1986.

MiYatake, T. and K. Hirahara, Three-dimensional velocity structure beneath the Japan Islands (III)., Progr. Abstr. Seismol. Soc. Jpn., 1, 288, 1989 (in Japanese).

OKADA, H., Forerunners of ScS waves from nearby deep earthquakes and upper mantle structure in Hokkaido, Zisin, 24, 228-239, 1971 (in Japanese with English abstract).

Romanowicz, B., Toward a federation of broadband seismic networks, EOS, Trans. Am. Geophys. Union, 67, 541-542, 1986.

Schultz, M. H., Spline Analysis, Prentice-Hall, Englewood Cliffs, New Jersey, 1973.

SENGUPTA, M. K., The structure of the earth's mantle from body wave observations, Sc.D. thesis, Mass. Inst. of Technol., Cambridge, 1-578, 1975.

SILver, P. G. and W. W. ChAN, Observations of body wave multipathing from broadband seismograms: Evidence for lower mantle slab penetration beneath the Sea of Okhotsk, J. Geophys. Res., 91, 13787-13802, 1986.

Sleep, N. H., Teleseismic P-wave transmission through slabs, Bull. Seismol. Soc. Am., 63, 1349-1373, 1973.

SMITH, W. D., A nonreflecting plane boundary for wave propagation problems, J. Comp. Phys., 15, 492-503, 1974.

SMITH, W. D., The application of finite element analysis to body wave propagation problems, Geophys. J. R. Astron. Soc., 42, 747-768, 1975.

SNOKE, J. A., I. S. SACKS, and H. OKADA, Determination of the subducting lithosphere boundary by use of converted phases, Bull. Seismol. Soc. Am., 67, 1051-1060, 1977.

STAUDER, W. and L. MUALCHIN, Fault motion in the larger earthquakes of the Kurile-Kamchatka arc and of the Kurile-Hokkaido corner, J. Geophys. Res., 81, 297-308, 1976.

Stefani, J. P., R. J. Geller, and G. C. Kroeger, A direct measurement of the distance between a hypocenter in a Benioff-Wadati zone and the slab-asthenosphere contact, $J$. Geophys. Res., 87, 323-328, 1982.

TARANTOLA, A. and B. VALETTE, Generalized nonlinear inverse problems solved using the least squares criterion, Rev. Geophys. Space Phys., 20, 219-232, 1982.

Toksöz, M. N., J. W. MINEAR, and B. R. JULIAN, Temperature field and geophysical effects of a downgoing slab, J. Geophys. Res., 76, 1113-1138, 1971.

UTSU, T., Regional variation of travel-time residuals of $P$ waves from nearby deep earthquakes in Japan and vicinity, J. Phys. Earth, 23, 367-380, 1975.

VIDALE, J. E., Waveform effects of a high-velocity, subducted slab, Geophys. Res. Lett., 14, 542-545, 1987.

Wiggins, R. A., The general linear inverse problem: Implication of surface waves and free oscillations for earth structure, Rev. Geophys. Space Phys., 10, 251-285, 1972.

Zienkiewicz, O. C., The Finite Element Method, 3rd ed., McGraw-Hill, New York, 1977. 